\title{
ARTICLE OPEN Macrophages promote epithelial proliferation following infectious and non-infectious lung injury through a Trefoil factor 2-dependent mechanism
}

\author{
Li-Yin Hung ${ }^{1}$, Debasish Sen ${ }^{2}$, Taylor K. Oniskey ${ }^{1}$, Jeremey Katzen ${ }^{3}$, Noam A. Cohen ${ }^{4}$, Andrew E. Vaughan ${ }^{5}$, Wildaliz Nieves ${ }^{1}$, \\ Anatoly Urisman ${ }^{2}$, Michael F. Beers ${ }^{3,6}$, Matthew F. Krummel ${ }^{2}$ and De'Broski R. Herbert ${ }^{1}$
}

Coordinated efforts between macrophages and epithelia are considered essential for wound healing, but the macrophage-derived molecules responsible for repair are poorly defined. This work demonstrates that lung macrophages rely upon Trefoil factor 2 to promote epithelial proliferation following damage caused by sterile wounding, Nippostrongylus brasiliensis or Bleomycin sulfate. Unexpectedly, the presence of T, B, or ILC populations was not essential for macrophage-driven repair. Instead, conditional deletion of TFF2 in myeloid-restricted CD11 ${ }^{\text {Cre }}$ TFF2 ${ }^{\text {flox }}$ mice exacerbated lung pathology and reduced the proliferative expansion of CD45 $\mathrm{EpCAM}^{+}$pro-SPC ${ }^{+}$alveolar type 2 cells. TFF2 deficient macrophages had reduced expression of the Wnt genes Wnt4 and Wnt16 and reconstitution of hookworm-infected CD11 $c^{\text {Cre }}$ TFF2 ${ }^{\text {flox }}$ mice with rWnt4 and rWnt16 restored the proliferative defect in lung epithelia post-injury. These data reveal a previously unrecognized mechanism wherein lung myeloid phagocytes utilize a TFF2/Wnt axis as a mechanism that drives epithelial proliferation following lung injury.

Mucosal Immunology (2019) 12:64-76; https://doi.org/10.1038/s41385-018-0096-2

\section{INTRODUCTION}

Tissue injury is inevitable, making regeneration fundamental to evolutionary fitness. Regeneration of epithelia following lung tissue damage is particularly important, because proximal (airway) and distal (alveolar) compartments form a dynamic barrier against environmental stimuli. ${ }^{1}$ Alveolar gas exchange function is under constant threat from inspired air containing potentially harmful chemical, mechanical, and infectious agents. Damage-induced loss of alveolar type I cells (ATI) would impair lung function, if not replenished by distal lung stem cells. ${ }^{2-4}$ Even though the yolk-sac derived alveolar macrophages (AM) are a major constituent of distal lung tissue, whether AM or myeloid cells in general are important drivers of epithelial replenishment following lung injury is poorly understood. 5,6

Classification of tissue macrophages $(M \varphi)$ into classically activated (M1) or alternatively activated (M2) subsets only partially defines $M \varphi$ heterogeneity. 7,8 Type 2 cytokines (e.g., interleukin 4 and 13) induce M2 cells that regulate pathogenic inflammation ${ }^{9}$ and purportedly drive repair, but there is scant evidence showing that M2 cells induce epithelial cell proliferation. ${ }^{10,11} \mathrm{M} 2$ secreted factors include: Amcase, Arginase I, chitinase-like proteins (Ym1/ Ym2), resistin-like molecule alpha (Relm-a), interleukin 10 and transforming growth factor beta (TGF- $\beta$ ), all of which are immunoregulatory, but not necessarily regenerative. ${ }^{12}$ In certain contexts, M $\varphi$ secrete Wingless-Int (Wnt) glycoproteins, ${ }^{13,14}$ a family of regenerative molecules controlling epithelial cell proliferation, differentiation, and polarity. ${ }^{15}$ Wnt's function through Frizzled receptors for $\beta$-catenin-dependent transcription, ${ }^{16}$ but also signal through non-canonical pathways that rely upon calcium/calmodulin-dependent protein kinases (e.g., Camkk2b). Irrespective of the pathway engaged, whether specific cytokines or epithelial secreted factors induce $M \varphi$ to produce Wnt's or other epithelial regenerative molecules is unknown.

Trefoil factor family (TFF1, TFF2, TFF3) molecules are small, reparative cytokines $(6-18 \mathrm{kDa})$ that promote rapid movement of epithelia over denuded basement membrane. ${ }^{17}$ Mouse strains deficient for Tff1, Tff2, or Tff3 possess constitutive defects in gastrointestinal (GI) barrier function, ${ }^{18-20}$ but the critical source(s) and function(s) for TFF's in non-Gl tissues are unclear. Even though Tff 2 can be produced by gastric epithelia, peritoneal macrophages and splenic T lymphocytes, ${ }^{21}$ how this molecule regulates epithelial repair is understudied. Tff2 deficiency in all of its potential cellular sources exacerbated lung damage caused by the murine hookworm Nippostrongylus brasiliensis (N.b.), and recent data shows that both BM-derived and nonBM-derived TFF2 drives repair. $^{22,23}$ Moreover, recent demonstration that myeloid cells influenced by Type 2 immune responses (i.e., IL-4Ralpha signaling) regenerate lung following partial pneumonectomy, ${ }^{24}$ prompted speculation that $M \varphi$ could repair damaged lung tissue by producing TFF2.

This study demonstrates myeloid-specific deletion of TFF2 impairs epithelial proliferation in three different models of lung

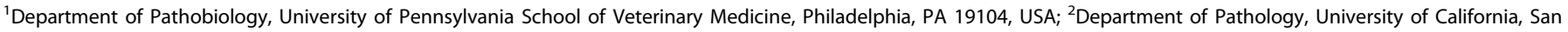

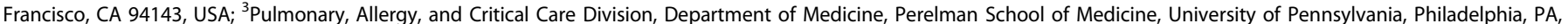

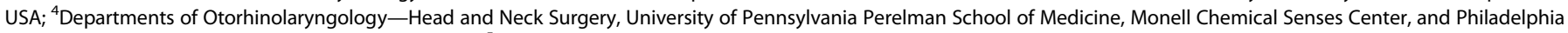

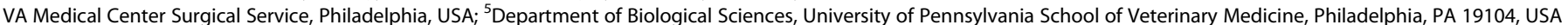
and ${ }^{6}$ PENN Center for Pulmonary Biology, University of Pennsylvania, Perelman School of Medicine, Philadelphia, Pennsylvania, USA

Correspondence: De'Broski R. Herbert (debroski@vet.upenn.edu)
}

Received: 22 August 2017 Revised: 16 September 2018 Accepted: 17 September 2018

Published online: 18 October 2018 
injury. Surprisingly, we found no evidence for interleukin 4 receptor alpha (IL-4Ra) expression in lung repair, suggesting the classical model of M2 polarization as pro-reparative is extremely context dependent. ${ }^{10}$ Recombination activating gene/common gamma c chain deficient $\left(\mathrm{RAG}_{\mathrm{C}} \mathrm{c}^{--}\right)$animals also had no defects in epithelial proliferation post-injury, indicating that neither adaptive lymphocytes or ILC were required in these systems. Instead, macrophages could directly promote epithelial proliferation in the absence of other cell types in a co-culture system containing either tracheal or alveolar type 2 cells (AT2). One demonstrated mechanism was that myeloid-intrinsic TFF2 was required for myeloid-derived Wnt gene expression (Wnt4 and Wnt16). Indeed, Wnt protein administration restored AT2 proliferation in myeloidspecific TFF2 mutants. This work supports a model wherein myeloid-epithelial cell interactions induce epithelial cell proliferation to restore damaged pulmonary tissue.

\section{RESULTS}

Proliferation of lung epithelia following hookworm-induced injury depends on the presence of lung macrophages

En route to the intestine, migratory hookworm larvae transiently damage alveolar architecture, ${ }^{25}$ but how pulmonary tissue repairs is unknown. Type 2 cytokines such as IL- 4 and IL- 13 are considered key mediators of wound healing, at least in part, through driving M2 macrophage polarization. ${ }^{12}$ N.b. infection causes a transient petechial lung injury that peaks by $\mathrm{d} 3$ and resolves by d9 (Fig. 1a), therefore we postulated that $M 2$ proliferative expansion was prerequisite for repair of N.b.-damaged lungs, as IL-4 drives $M \varphi$ proliferation in situ. ${ }^{26,27}$ Immunofluorescence lung tissue staining for Chitinase like $3 / \mathrm{Ym} 1$ (a M2 marker) ${ }^{10}$ and Ki-67 (cell-cycle protein) were used to decipher whether M2 cells underwent proliferative expansion following hookworm injury (Fig. 1c and Supplemental Fig. 1a-b). Data show that from pre-infection to d9 post-infection the overall $\mathrm{Ki}-67^{+}$cell numbers accumulated during the course of infection while numbers of $\mathrm{Ym}^{+}$cells remained somewhat similar (Fig. 1b, c). Proliferating $M \varphi,\left(\mathrm{Ym}^{+} / \mathrm{Ki}-67^{+}\right)$ were detected between $\mathrm{d} 3-9$, but most of the Ki- $67^{+}$cells in the lung did not co-express Ym1 (Fig. 1b-e). Thus, contrary to expectation, most of the proliferating cells within hookwormdamaged lungs were not $M 2$ cells.

We asked whether the non-myeloid cells that were $\mathrm{Ki}-67^{+}$were epithelial cells because hookworm infection causes a defect in pulmonary gas exchange. ${ }^{28}$ To determine whether lung epithelia were indeed entering the S-phase during the recovery from hookworm-injury, we devised a flow cytometry strategy (Supplemental Fig. 1c) that utilized either an EdU or BrdU pulse at $24 \mathrm{~h}$ prior to euthanasia on different days post-infection (d0,1, 3, 5, 7, and 9) followed by identification of cells that were $\left(\mathrm{BrdU}^{+}, \mathrm{CD} 45^{-}\right.$, $\mathrm{EpCAM}^{+}$) using flow cytometry. Data show that the percentages of $\mathrm{BrdU}^{+}, \mathrm{EpCAM}^{+}$cells increased 3-fold over baseline at d3 and 19fold between d5-7 post-infection (Fig. 1f, g). Strikingly, the infection-induced increase in proliferating epithelia was unabated in IL-4Ra ${ }^{-/-}$and recombination activating gene $1 /$ common gamma c chain (RAG $\mathrm{Yc}^{-1}$ ) deficient strains (Fig. 1h). These data indicated that the proliferative expansion of epithelia following N.b. infection did not require IL-4/IL-13 responsiveness, T, B, or ILC populations.

To address whether local tissue $M \varphi$ regulated epithelial proliferation in the damaged lung tissue, mice were generated to co-express the reverse tetracycline-controlled transactivator (rtTA) under control of the human CD68 promoter with a diphtheria toxin A transgene under control of the tetracycline operator (TetO-DTA). This strain (referred to as CD68-DTA) was compared to single transgenic CD68rtTA controls (CD68). The specificity and duration of $M \varphi$ deletion in this strain following systemic tetracycline administration has been previously described. ${ }^{29}$ To confirm that lung $M \varphi$ depletion could be achieved during N.b. infection, CD68 and CD68-DTA mice were administered $250 \mathrm{ng}$ intranasal (i.n.) anhydrotetracyline (Ahtet) on day's $-4,-2,0$, and 2 post-infection. Analysis at d4 post-infection demonstrated selective deletion of two populations within lung digests: (a) auto-fluorescent, CD11 $\mathrm{c}^{+}$, Siglec $^{+} \mathrm{F}^{+}$and (b) CD11 bow/ med $\mathrm{MHCll}^{+}, \mathrm{CD}_{103}$ cells, indicating selective depletion of AM and interstitial macrophages (IM), respectively (Fig. 2a, b). Using this $\mathrm{M} \varphi$ depletion protocol, data showed that in comparison to CD68 controls, proliferating $\mathrm{SPC}^{+}$epithelia (ATII cells) in parasitized CD68-DTA mice were 3 -fold reduced by $\mathrm{d} 3$ and 4 -fold reduced between $\mathrm{d} 5$ and $\mathrm{d} 7$ post-infection (Fig. $2 c$, d). Lung $M \varphi$ depletion had no impact upon worm expulsion from the intestine (data not shown).

Next, blood oxygen content $\left(\mathrm{SpO}_{2}\right)$ was measured to determine if lung $M \varphi$ affected the $\Delta \mathrm{SpO}_{2}$ levels at d3-9 post-infection. Data show that although the $\mathrm{d} 3 \mathrm{SpO}_{2}$ nadir was equivalent between strains, CD68 controls rapidly recovered following worm egress, whereas CD68-DTA mice remained $10 \%$ lower than baseline at both $d 7$ and $d 9$ (Fig. 2e), indicating an important role for $M \phi$ in promoting lung repair following hookworm infection.

Lung TFF2 expression is induced by hookworm infection in the absence of IL-4 receptor

$\mathrm{M} \varphi$ can be a direct source of various repair proteins ${ }^{13,14}$ and since Tff2 was induced in N. brasiliensis-infected lungs in the absence of IL-4Ra signaling (Supplementary Figure 1e), subsequent experiments addressed whether myeloid-derived TFF2 was involved in lung repair. TFF2 conditionally deficient mice on a C57BL/6 background were generated by expressing an internal ribosomal entry site-fluorescent tandem dimer (td)-Tomato cassette (IRES-TdTomato) immediately following the stop codon in exon 4 of Tff2, with two IoxP sites flanking exons 2 and $3^{\prime}$ UTR (Fig. $3 a$ and Supplementary Figure 2a). TFF2-tdTomato flox mice (designated "Tre-Tom") had no gross abnormalities and were born at the expected female:male ratios. Site-specific recombination and germ-line transmission were confirmed by Southern blot (Supplementary Figure 2b). As expected, Tff2 mRNA was constitutively expressed in a small population of $\mathrm{Td}^{- \text {tomato }^{+}}$gastric epithelial cells sorted from the stomach tissue of naive Tre-tom mice (Supplementary Figure 2c and data not shown), which was consistent with Tff2 expression in the stomach. ${ }^{30}$

To evaluate the Tff2 expression in the pulmonary compartment, $300 \mu \mathrm{m}$ sections of agarose-filled lung tissue were prepared using established methods ${ }^{31}$ and subjected to confocal imaging under steady-state and infectious conditions. Whereas baseline Tdtomato expression was sparse, but punctate within the distal lung compartment under steady-state conditions (Fig. 3b), there were large, focal aggregates of $\mathrm{Td}^{-T_{0}}$ mato $^{+}$cells within the alveolar compartment at $\mathrm{d} 4$ following hookworm infection (Fig. 3c, d). These data indicated that infection-induced an increase of TFF2 expression occurred within large cells in the alveoli. Based on their morphology and location, we hypothesized that some of these large TFF2 positive cells were of a hematopoietic lineage.

CD11c-mediated TFF2 deletion impairs epithelial proliferation following infectious lung injury

CD11c ${ }^{\text {Cre }}$ TFF2 ${ }^{\text {flox }}$ mice were generated through intercross between Tre-tom and $\mathrm{CD} 11 \mathrm{c}^{\mathrm{Cre}}$ strains to test whether myeloidderived TFF2 was biologically important. ${ }^{32}$ Real-time PCR was used to compare Tff2 mRNA transcript levels between TFF2 deficient, CD11 $c^{\text {Cre } T F F 2 ~}{ }^{\text {flox }}$ and CD11c Cre controls in four distinct FACSsorted lung populations: lung epithelia $\left(C D 45^{-} E p C A M^{+}\right), A M$ $\left(\mathrm{CD}_{64}^{+}, \mathrm{CD} 11 \mathrm{~b}^{-}, \mathrm{CD} 11 \mathrm{c}^{+}\right), \mathrm{IM}\left(\mathrm{CD}^{+} 4^{+} . \mathrm{CD} 11 \mathrm{~b}^{+}, \mathrm{CD} 11 \mathrm{c}^{-}\right)$, and

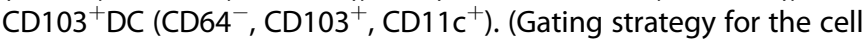
sorting is shown in (Supplementary Figure 3a). Results show that AM underwent infection-induced Tff2 expression by $\mathrm{d} 4$ postinfection (Fig. 3e, f). TFF2 was also evident in CD103 DC and interstitial macrophages and expression was lost in 


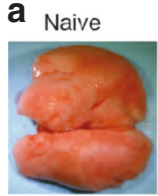

d5

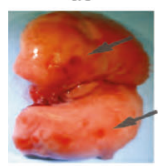

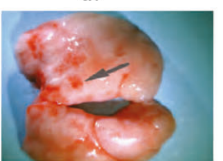

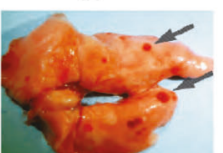

7

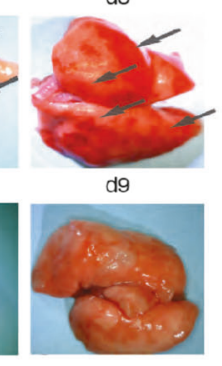

d3

b

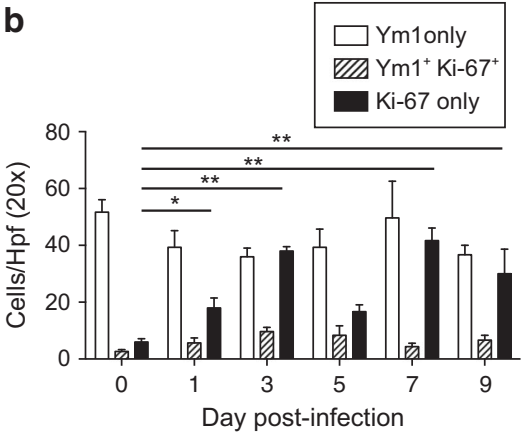

C
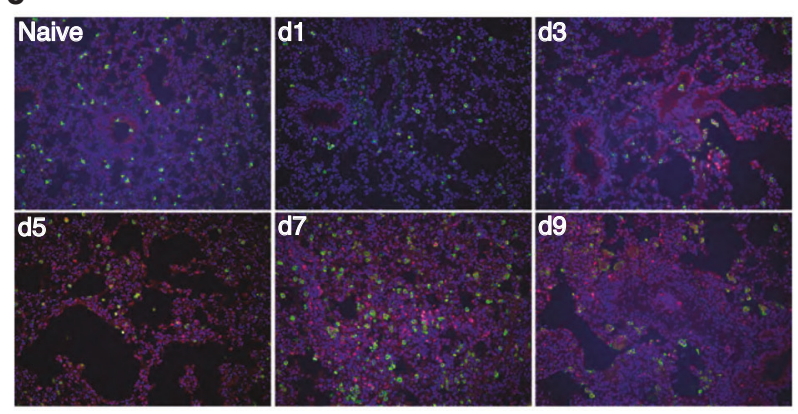

d

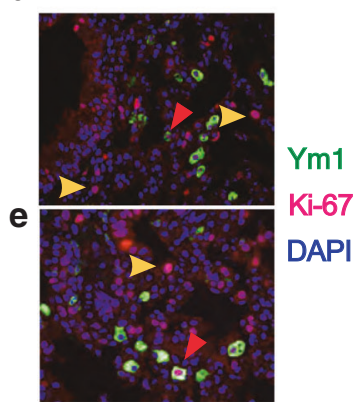

f
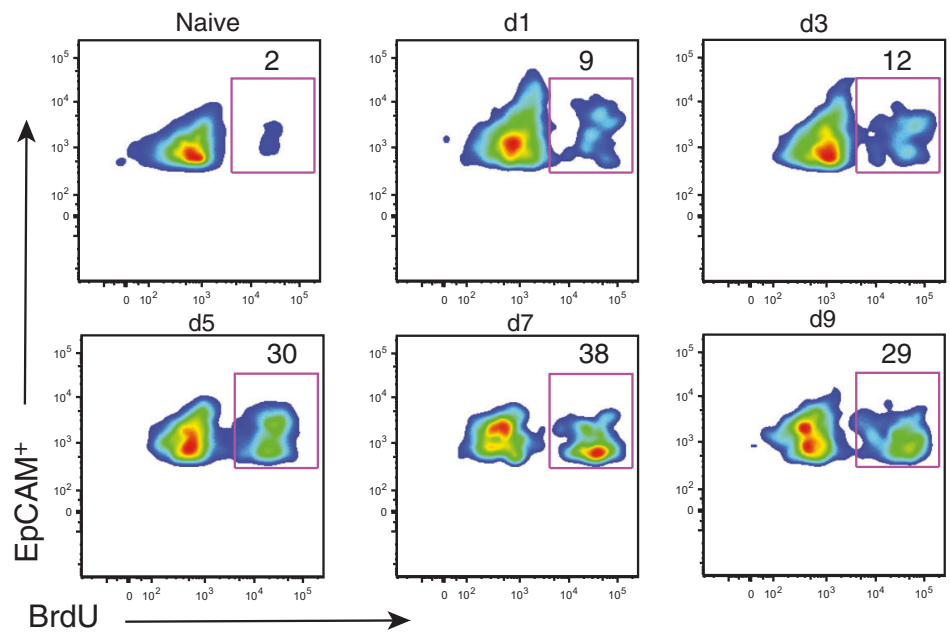

g
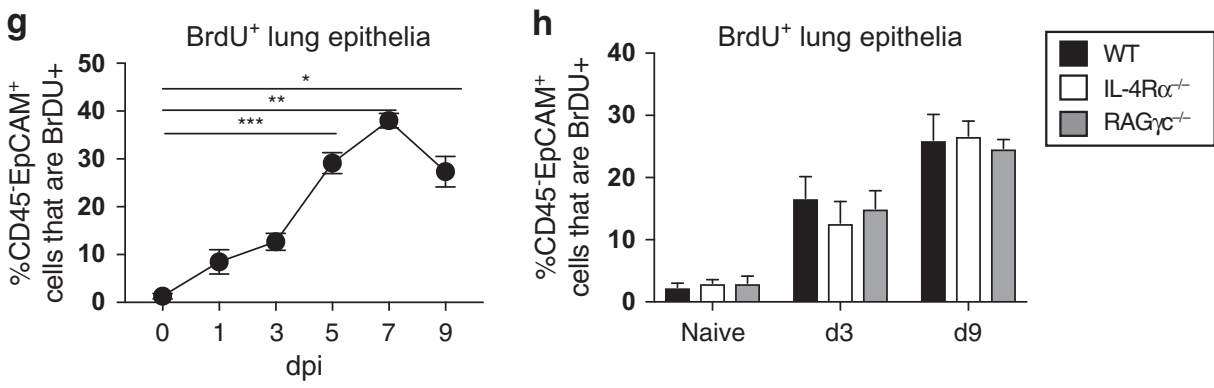

Fig. 1 Epithelial proliferation after Nippostrongylus brasiliensis (N.b.) infection. a Representative photographs of lung tissues from naive or infected WT C57BL/6 mice at various time-points following subcutaneous infection of $650 \mathrm{~L}_{3} \mathrm{~N} . b$.. Arrows point to focal areas of hemorrhagic injury. All images were taken at 20x with Dino-Lite Pro Digital Microscope via Dino Capture 2.0 software. b Quantifications of Ym $1^{+}, Y_{m} 1^{+}$Ki$67^{+}$, and Ki-67+ during N.b. infection. For each time-point, 5 randomly selected fields under 20x were counted. c Kinetic analysis of Ym1 (Cy2) and $\mathrm{Ki}-67$ (Cy3) immunostaining within FFPE distal lung tissues of naïve or N.b.-infected mice at the time-points indicated. 200x magnification. d, e Images of $\mathbf{d}$ d3 3 and e d7 post-infection lung tissues at 400x. Yellow arrowheads indicate Ki- $67^{+}$cells and red arrowheads indicate Ki-67 ${ }^{+}$ $/ \mathrm{Ym}^{+}$co-staining, respectively. DAPI counterstain is shown in blue. $\mathbf{f}$ Pseudo-color flow plots showing distal lung total live CD45 neg cells gated for $\mathrm{EpCAM}^{+}$cells that were BrdU ${ }^{+}$at the indicated time-points following N.b. infection. $\mathbf{g}$ Quantification of cells gated as in $\mathbf{f}$ isolated from WT C57BL/6 mice. $\mathbf{h}$ Comparison of cells gated as in $\mathbf{f}$ from WT, IL-4R $\alpha^{-/-}$and RAG $\gamma \mathrm{c}^{-/-}$strains at indicated time points. $n=4$ mice/group. Mean \pm SEM are shown. ${ }^{*} p<0.05,{ }^{* *} p<0.01$, and ${ }^{* * *} p<0.005$ via ANOVA. Representative data from three independent experiments 


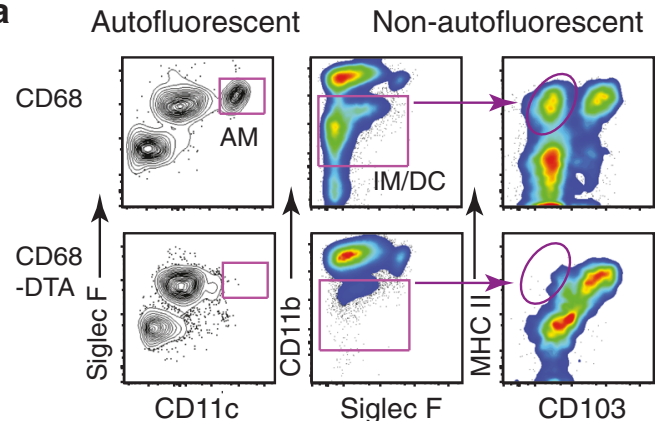

C
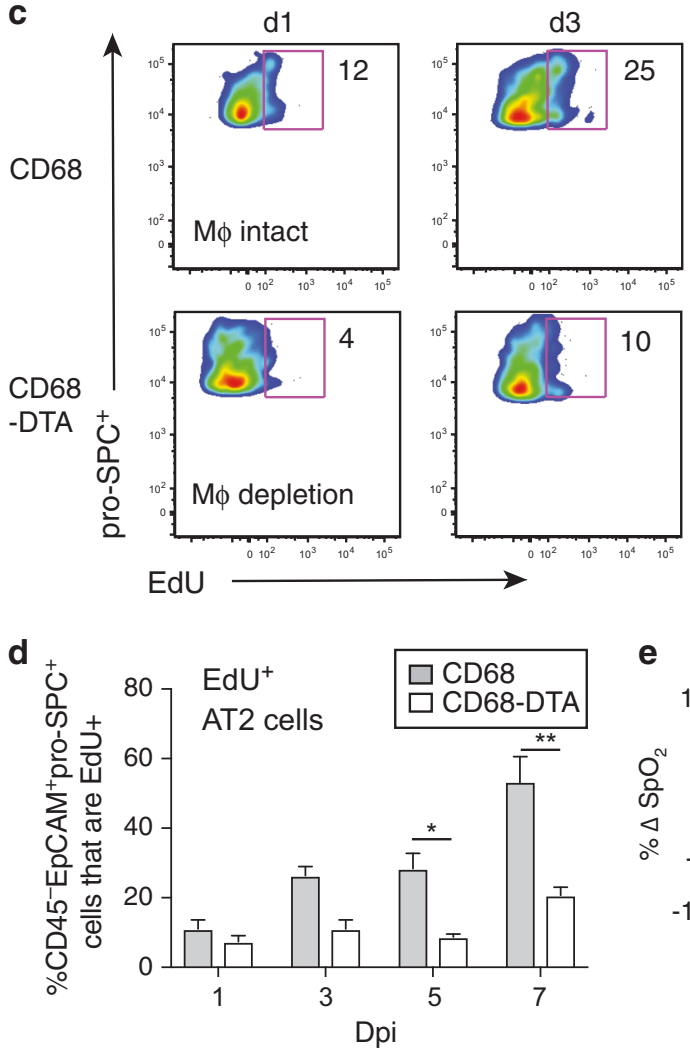

b

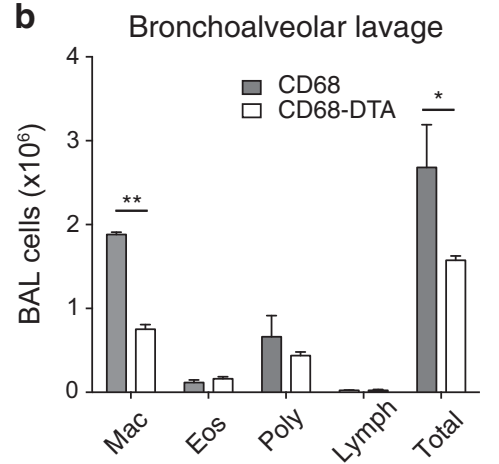

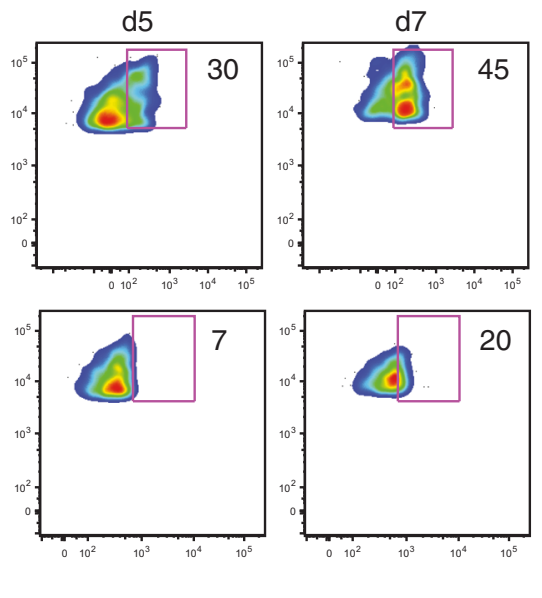

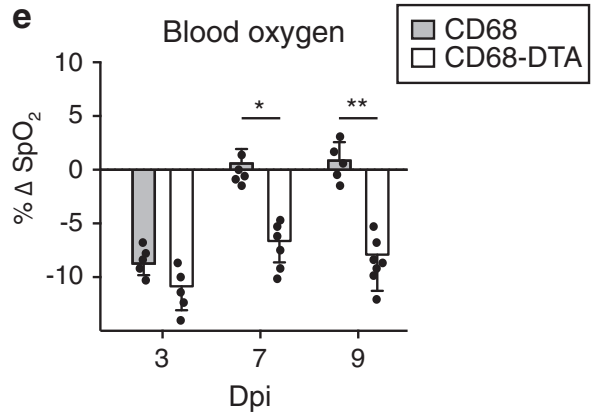

Fig. 2 Myeloid cells are required for epithelial proliferation after N.b. infection. Anhydrotetracycline (Ahtet) was administered i.n. (250 ng/ dose) on $\mathrm{d}-4, \mathrm{~d}-2, \mathrm{~d} 0$, and $\mathrm{d} 2$ of $N . b$. infection protocol: a Flow cytometry plots showing deletion specificity within whole lung digests and b differential counts of cells recovered from bronchoalveolar lavage fluid of CD68-rtTA (CD68) vs. CD68-rtTA-TetO-DTA (CD68-DTA) mice at d4 following N.b. infection. c Representative flow plots and d quantification total live CD45 neg cells gated for EpCAM ${ }^{+}$cells that were pro-SPC ${ }^{+}$ and $\mathrm{BrdU}^{+}$from CD68 and CD68-DTA lungs on indicated day post N.b. infection (Dpi). e Percent change in blood oxygen content (SpO ${ }_{2}$ ) normalized to baseline levels at the indicated time-points post-N.b. infection (Dpi). Each symbol indicates individual mouse. ${ }^{*} p<0.05,{ }^{* *} p<$ 0.01 via Student's $t$-test. Mean \pm SEM are shown. Representative data from three independent experiments

$\mathrm{CD} 11 \mathrm{c}^{\mathrm{Cre}} \mathrm{TFF2}{ }^{\text {flox }}$ mice (Supplementary Figure 3b). Curiously, Tff2 transcripts were higher in lung epithelia sorted from CD11 $c^{\text {Cre }}$ TFF2 ${ }^{\text {flox }}$ mice than epithelia in CD11 $c^{\text {Cre }}$ controls (Fig. 3e, f), suggesting a compensatory Tff2 up-regulation in epithelial cells due to deletion in the myeloid compartment.

CD11C Cre TFF2 flox mice had a reduced percentage of $\mathrm{BrdU}^{+}$cells within alveolar type 2 cell populations $\left(\mathrm{CD}_{4} 5^{-}\right.$. $\mathrm{EpCAM}^{+}$, pro$\mathrm{SPC}^{+}$) when compared to $\mathrm{CD} 11 \mathrm{c}^{\mathrm{Cre}}$ controls at day 9 postinfection (Fig. $3 \mathrm{~g}$ and Supplementary Fig $4 \mathrm{a}$ ). $\mathrm{SpO}_{2}$ levels were significantly lower in $\mathrm{CD} 11 \mathrm{c}^{\mathrm{Cre}} \mathrm{TFF} 2^{\text {flox }}$ mice at $\mathrm{d} 9$ post-infection, implying a defect in lung function rebound (Fig. 3h). Concerning the initial injury caused by larvae, the BAL RBC numbers were increased at day 3 , reflective of more severe injury in $\mathrm{CD}_{11 \mathrm{C}^{\mathrm{Cre}} \mathrm{TFF}^{\text {flox }}}$ mice compared to $\mathrm{CD}_{11 c^{\text {Cre }}}$ controls (Supplementary Figure 4b). The alveolar space within infected
CD11 $c^{\text {Cre }}$ TFF2 ${ }^{\text {flox }}$ mice was markedly larger than CD11 $c^{\text {Cre }}$ controls evidenced by areas of enlarged airspace (Fig. 3i) suggesting that resolution of hookworm injury that was abnormal in CD11c Cre TFF2 ${ }^{\text {flox }}$ mice.

Next, the bleomycin model of lung injury was used to determine whether myeloid-derived TFF2 was important for lung repair in a non-infectious context lacking excess Type 2 cytokine production. ${ }^{33}$ Acute cytotoxicity of bleomycin causes severe alveolar cell damage, transient weight loss, pulmonary inflammation, and chronic collagen accumulation.2 Bleomycin treatment transiently increased BAL TFF2 levels in both mouse strains, whereas $C D 11 c^{\text {Cre }}$ controls underwent a 3 -fold increase at $d 9$, this early induction was reduced by myeloid-specific TFF2 deficiency (Fig. 4a). On the other hand, CD11 $\mathrm{C}^{\mathrm{Cre}} \mathrm{TFF} 2^{\text {flox }}$ mice produced higher TFF2 levels than $\mathrm{CD}_{11} \mathrm{c}^{\mathrm{Cre}}$ controls by $\mathrm{d} 16$, suggestive of 
a

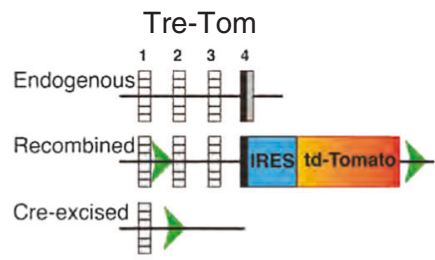

e

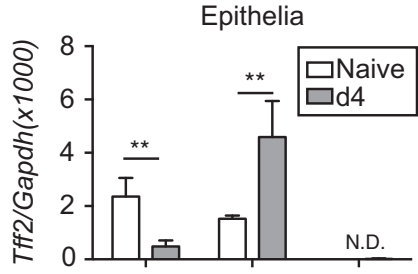

f

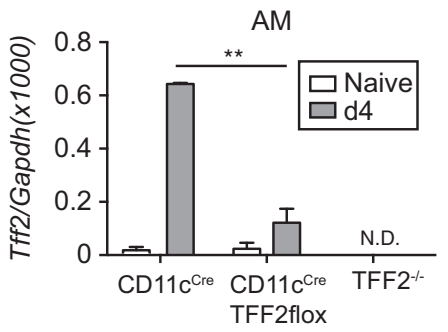

g

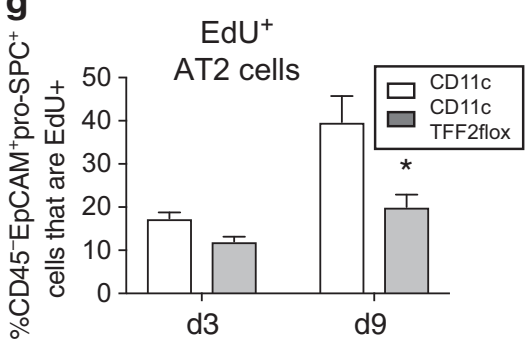

h

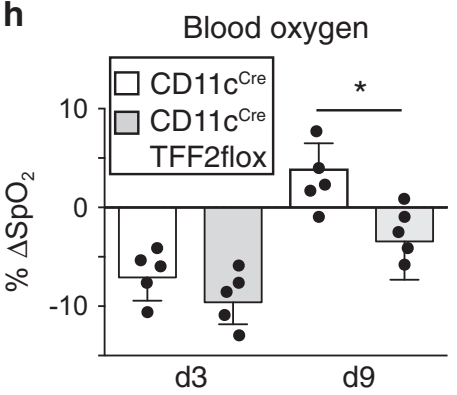

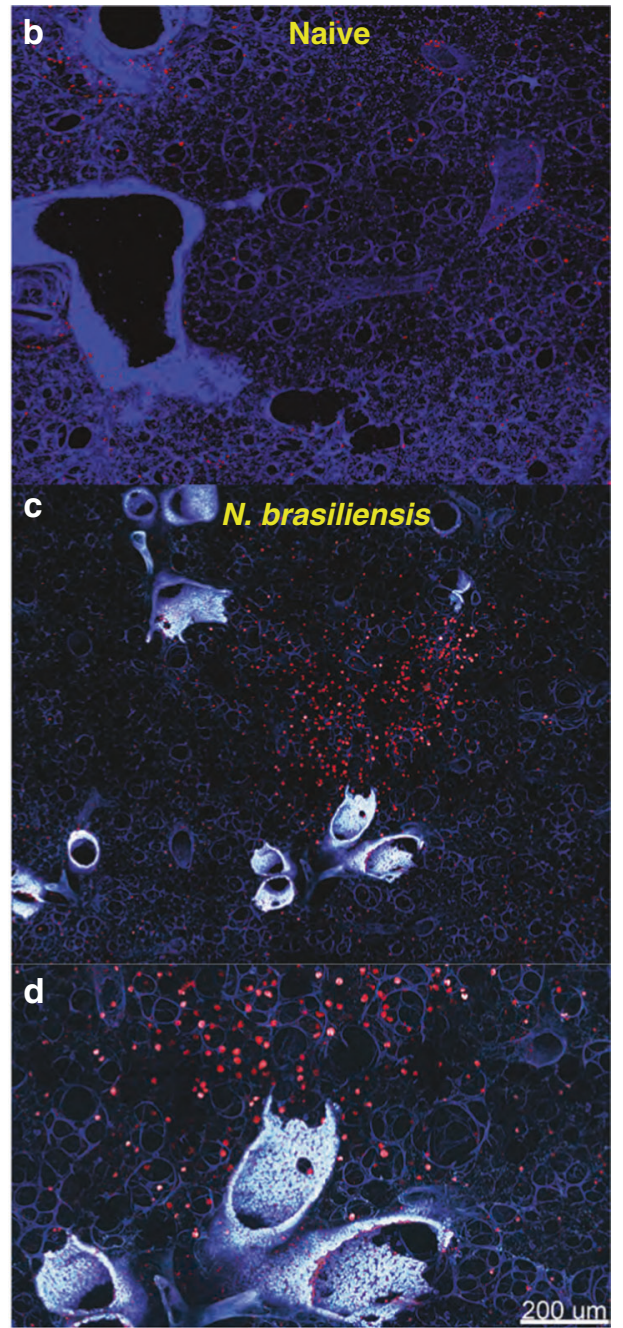

i

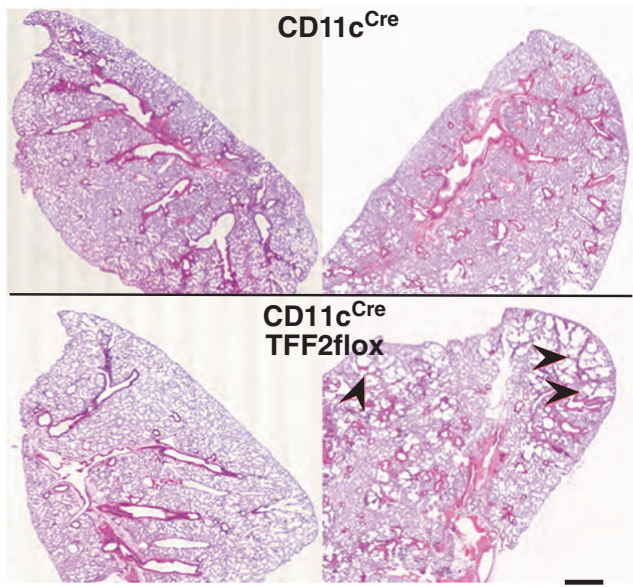

Fig. 3 CD11c-specific TFF2 deletion exacerbates lung pathology following N.b. -induced injury. a Schematic illustration of TFF2-flox/reporter (Tre-Tom) generation. b-d Confocal microscopy images showing baseline expression of TFF2 in agarose-inflated lung tissues of $\mathbf{b}$ naïve and c, d N.b.-infected TFF2-TdTomato fluorescent reporter (Tre-Tom) mice on d4 at c 200x and d 400x. e, f Quantitative Tff2 mRNA levels in sorted

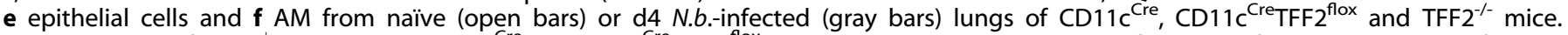
g Percentages of $\mathrm{BrdU}^{+} \mathrm{AT} 2$ cells in $\mathrm{CD} 11 \mathrm{c}^{\mathrm{Cre}}$ vs. CD11 $\mathrm{c}^{\mathrm{Cre}}-\mathrm{TFF} 2^{\text {flox }}$ lungs at indicated time-points after N.b. infection. $\mathbf{h}$ Change of blood oxygen levels from baseline at $\mathrm{d} 3$ and $\mathrm{d} 9$ following N.b. infection in CD11 $c^{\text {Cre }}$ and $C D 11 c^{C r e} T F F 2^{\text {flox }}$ mice. i Representative lung pathology of naïve (left) and d9 following N.b. infection (right) in CD11 $c^{\text {Cre }}$ and CD11 $c^{\text {Cre }}$ TFF2 ${ }^{\text {flox }}$ mice. Arrowheads indicate emphysematous areas. 20x magnification. ${ }^{*} p<0.05,{ }^{* *} p<0.01$ determined by ANOVA or Student's $t$-test. Mean \pm SEM are shown 

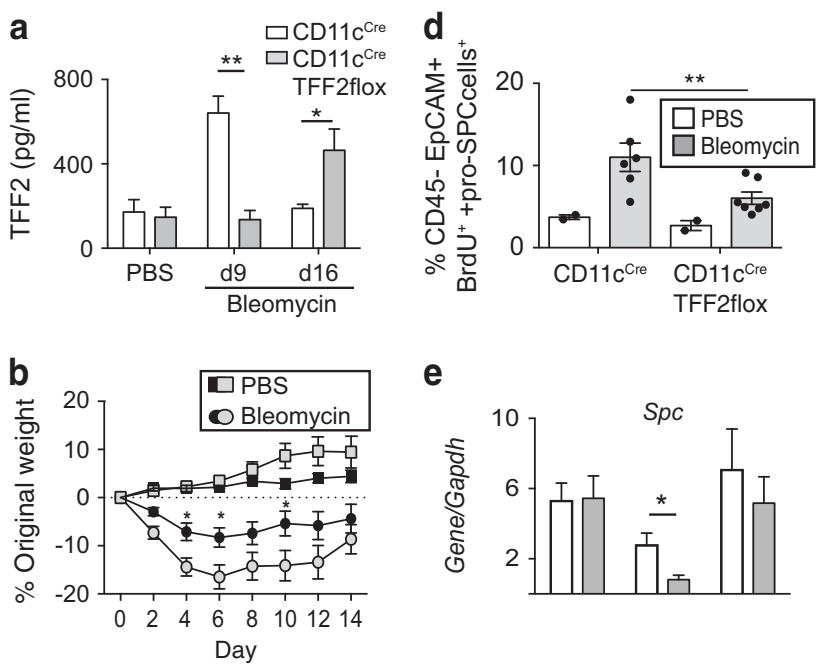

e

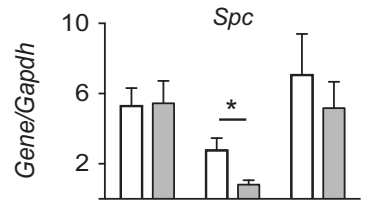

C
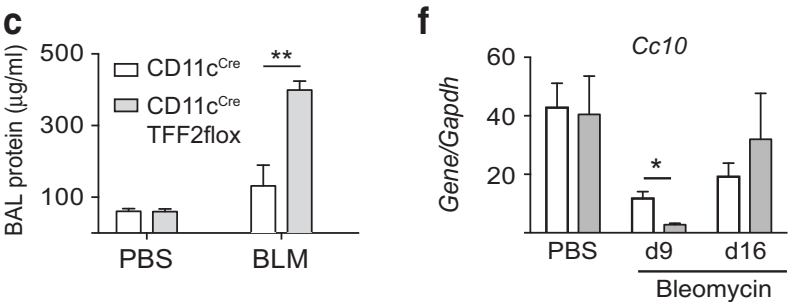

Fig. 4 CD11c-specific TFF2 expression is critical for lung epithelial proliferation and recovery from Bleomycin-induced pathology. a BAL TFF2 levels from PBS-treated or at d9 or d16 after Bleomycin (BLM) treatment in CD11c ${ }^{\text {Cre }}$ and CD11 $c^{\text {Cre }}-$ TFF2 ${ }^{\text {flox }}$ mice. b Weight changes over two weeks after BLM treatment in CD11c ${ }^{\text {Cre }}$ (black symbols) and CD11 $c^{\text {Cre }}$-TFF2 ${ }^{\text {flox }}$ (gray symbols) mice. c Total protein levels in BAL from PBS-treated or d9 BLM-treated mice. d Percentage of $\mathrm{BrdU}+\mathrm{EpCAM}+$ cells in the lungs from PBS controls or on d9 after BLM treatment. Each symbol represents individual mouse. e, $\mathbf{f}$ Message RNA levels of e $S p C$ and $\mathbf{f} C c 10$ from lungs of PBStreated or d9/d16 BLM-treated CD11 $c^{\text {Cre }}$ (open bars) or CD11c ${ }^{\text {Cre }}$ TFF $2^{\text {flox }}$ (gray bars) mice. Mean \pm SEM are shown. ${ }^{*} p<0.05$ and ${ }^{* *} p<$ 0.01 as determined by ANOVA or Student's $t$-test. Representative results from three independent experiments were shown. $n=3-6 /$ group unless specified otherwise

compensatory production from a non-myeloid source at later stages when fibrosis occurs (Fig. 4a). CD11 $c^{\text {Cre TFF2 }}{ }^{\text {flox }}$ animals experienced a transient, but significantly greater weight loss than CD11c Cre controls during the acute injury phase, but subsequently recovered in the latter phase (Fig. 4b). At day 9, the total protein levels in BAL fluid is higher in CD11c Cre TFF2 ${ }^{\text {flox }}$ (Fig. 4c); also, the $\mathrm{CD}_{45}{ }^{-} \mathrm{EpCAM}^{+} \mathrm{BrdU}^{+}$pro-SPC ${ }^{+}$population of lung epithelia were significantly reduced in percentage from CD11 $c^{\text {Cre }}$ TFF2 ${ }^{\text {flox }}$ mice compared to CD11 $c^{\text {Cre }}$ mice (Fig. 4d), concordant with significantly reduced mRNA expression levels for Spc (encoding surfactant protein $\mathrm{C}$ ) and $\mathrm{CC} 10$ (encoding Clara cell $10 \mathrm{kDa}$ protein) at d9 (Fig. 4e, f). Taken together, these data demonstrate that lack of myeloid-derived TFF2 reduced epithelial proliferation during recovery from bleomycin injury.

$M \varphi$ promote epithelial regeneration through a TFF2-dependent mechanism

To determine whether $M \varphi$-driven epithelial proliferation following injury was direct or indirect processes, a co-culture system was developed to isolate the $M \varphi$-epithelial cell interaction in vitro. This system, referred to as the macrophage-epithelial repair assay (MERA) utilized primary mouse airway epithelial cells cultured under bi-phasic conditions (i.e., air-liquid interface) in transwell inserts with bone marrow $\mathrm{M} \varphi(\mathrm{BMM} \varphi)$ attached to the basolateral surface directly underneath. The two cell populations were separated across a semi-permeable barrier $(10 \mu \mathrm{m}$ thick with pore size $0.4 \mu \mathrm{m}$ ) and evaluated following a pipet-mediated scratch wound to the epithelial monolayer (Fig. 5a). Tracheal epithelia were initially used due to the high trans-epithelial cell resistance (TER) levels (generally $>1000 \Omega$ ). As expected, $M \varphi$ cultured alone lacked electrical resistance, but epithelia cultured alone maintained TER levels over $1000 \Omega$ (Fig. 5b).

Upon injury, $M \varphi$ significantly accelerated the TER rebound following pipet-mediated scratch because $M \varphi$-epithelia cocultures resulted in $100 \%$ restoration of baseline TER levels by d3, further increasing to $130 \%$ by d4 post-scratch (Fig. 5c). However, in the absence of $M \varphi$, the epithelia only recovered $65 \%$ of baseline TER levels by $\mathrm{d} 4$ post-injury (Fig. $5 \mathrm{c}$ ). The ability of $\mathrm{M} \varphi$ to promote TER rebound did not require $\mathrm{rlL}-4$ or $\mathrm{rlL}-13$ administration, nor were any defects in TER recovery observed using IL-4Ra ${ }^{-/-} \mathrm{M} \varphi$ (Fig. 5d). In contrast, using TFF2 deficient $\mathrm{M} \varphi$ reduced the re-epithelialization rate and resulted in only $45-50 \%$ TER restoration by $\mathrm{d} 4$ post-wounding (Fig. 5e). Detectable levels of TFF2 protein were found in MTEC supernatant lacking $M \varphi$, but the presence of $M \varphi$ increased supernatant TFF2 levels 2 -fold (Fig. $5 f$ ).

To determine whether epithelial barrier restoration and proliferation were functionally linked, BrdU incorporation was assessed on MTEC harvested on d4 and gated on EpCAM ${ }^{+}$, junctional adhesion molecule- $1\left(\mathrm{JAM}-1^{+}\right)$cells to ensure evaluation of mature epithelial cells devoid of macrophages (Fig. $5 \mathrm{~g}$ ). Of the live $\mathrm{EpCAM}^{+}$cells recovered from the apical side of the transwell insert, (Supplementary Figure 4c), only low levels of epithelial proliferation occurred in cultures lacking $M \varphi$, but the $\mathrm{BrdU}^{+}$epithelial population increased 7-fold with WT M $\varphi$ (Fig. 5h, i). $\mathrm{TFF}^{-/-} \mathrm{M} \varphi$ promoted a moderate increase in proliferation over cultures lacking $M \varphi$, but IL-4Ra ${ }^{-/-} M \varphi$ stimulated an 8-fold increase in $\mathrm{BrdU}^{+}$epithelia over cultures lacking $M \varphi$ (Fig. 5 j, k). In the absence of $M \varphi$, rTFF2 treatment increased proliferation only 2 -fold (Fig. 5l, m). Application of rTFF2 alone (without $M \varphi$ ) significantly accelerated TER rebound over the scratched, mock-treated cultures (Fig. 5n). Moreover, WT alveolar macrophages (AM) significantly accelerated TER restoration, but TFF2 ${ }^{-1-} \mathrm{AM}$ were less able to promote repair, whereas lack of TFF2 within the epithelia impaired TER rebound irrespective of the AM genotype (Fig. 5o).

To address whether macrophages also promoted recovery of epithelia population relevant to the distal lung compartment, primary alveolar type 2 (AT2) cells were used instead of MTEC. In this setting, WT $M \varphi$ also induced greater EdU incorporation (Fig. $5 p, q$ ) and TER recovery (Fig. $5 r$ ) than TFF2 ${ }^{-1-} M \varphi$. Taken together, $M \varphi$ induced recovery of epithelial barrier function and also epithelial proliferation through TFF2-dependent mechanism.

Macrophage-derived TFF2 is necessary for myeloid derived noncanonical Wnt expression

To further understand the mechanism acting downstream of TFF2 expression in myeloid cells, RNA-sequencing was completed on WT or TFF2 ${ }^{-/-}$BMM $\varphi$ recovered from MERA at $\mathrm{d} 4$ and compared to reads obtained from naïve $B M M \varphi$ exposed to quiescent MTEC. TFF2 mRNA transcripts were not different between WT $M \varphi$ exposed to intact or damaged epithelia (not shown), but we found that WT M $\varphi$ exposed to damaged MTEC up-regulated canonical M2 genes such as: Mgl2, Socs2, and Arg1 (Supplementary Figure 5a). However, comparison of RNA transcripts between WT and $\mathrm{TFF}^{-/-} \mathrm{M} \varphi$ that were both exposed to damaged MTEC revealed that Camkk2b expression was significantly ( $>2$-fold) under-represented in $\mathrm{TFF}^{-/-} \mathrm{M} \varphi$ (Supplementary Figure $5 \mathrm{~b}$ ). Because Camkk2b is implicated in the calcium dependent pathway for Wnt glycoprotein expression, ${ }^{34,35}$ which in turn regulates multiple aspects of epithelial cell biology, we reasoned that $M \varphi$ derived TFF2 may promote epithelial repair, at least partially, via regulating Wnt expression. 


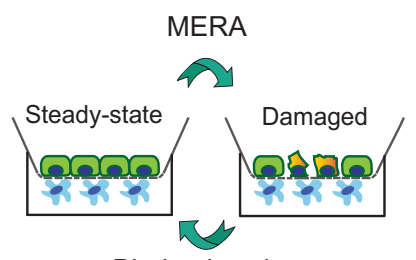

Bi-phasic culture

d

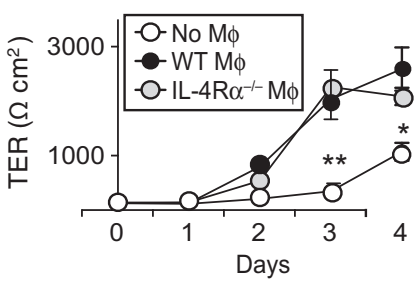

b
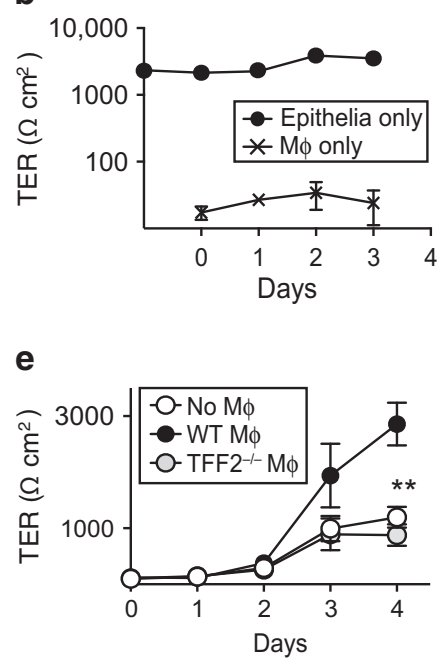

C

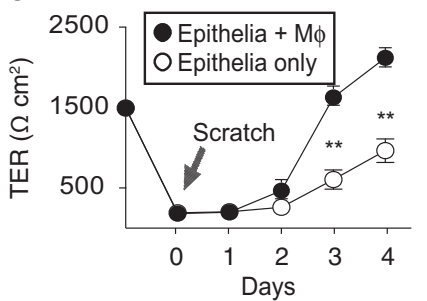

f

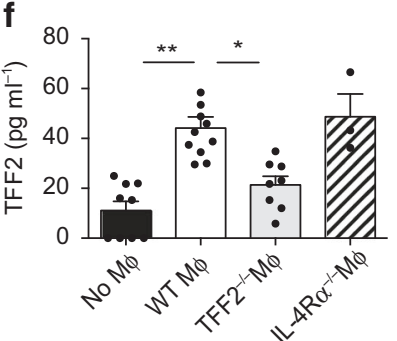

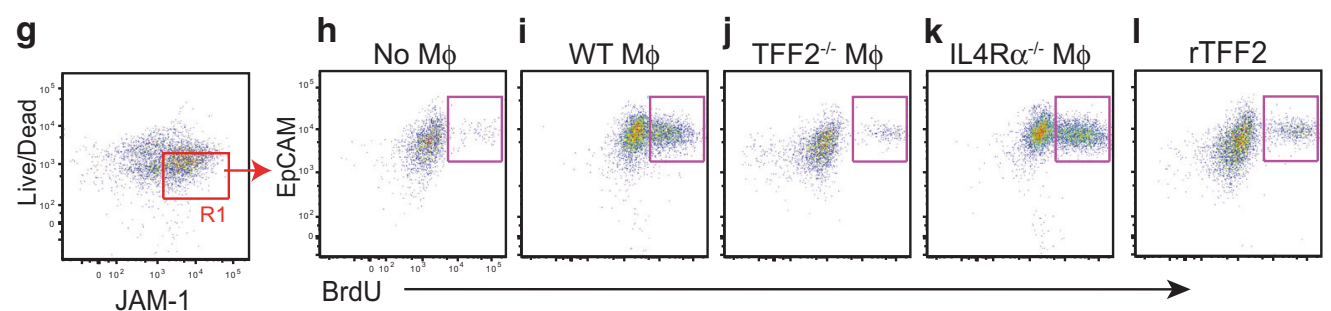

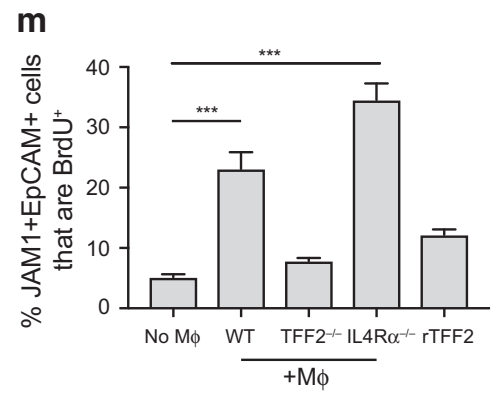

p

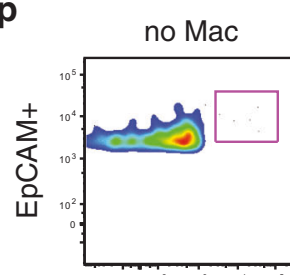

EdU n

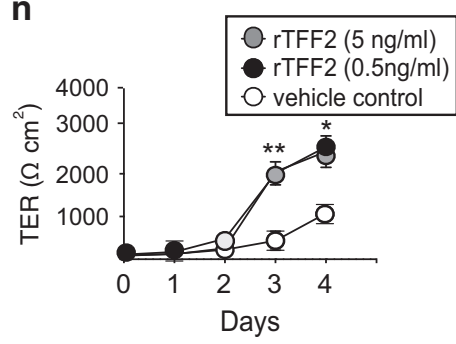

0

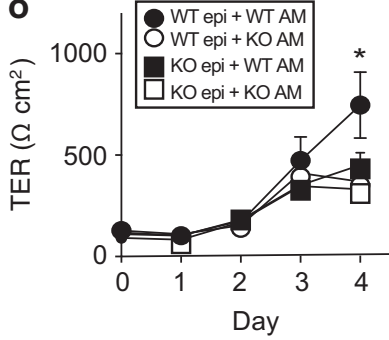

q
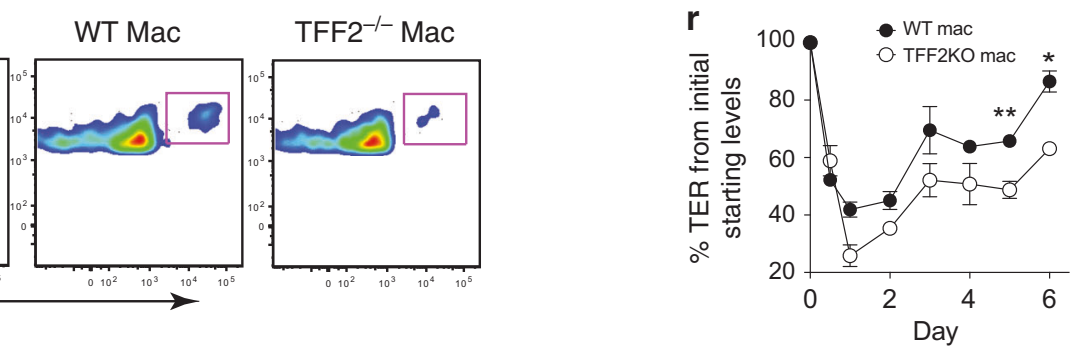

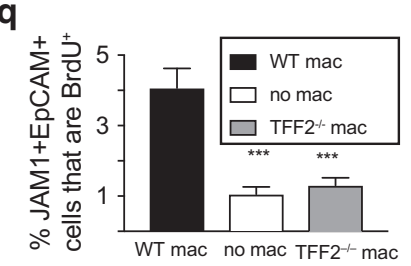

To test this hypothesis, cDNA-derived from different $M \varphi$ populations recovered from d4 of MERA were screened against a panel of 84 different Wnt pathway genes. Wnt4a and Wnt16 were 2 -fold increased in WT $M \varphi$ exposed to damaged epithelia vs. WT $M \varphi$ exposed to non-scratched, quiescent epithelia (Fig. 6a).
Remarkably congruent with our hypothesis, Wnt4a and Wnt16 were both 2-3-fold reduced in $\mathrm{Tff}^{-/-} \mathrm{M} \varphi$ exposed to injured epithelia compared to WT $M \varphi$ exposed to injured epithelia (Fig. 6b). Inoculation of WT MERA cultures with anti-Wnt4 Ab abrogated the TER rebound compared to control IgG treatment 
Fig. 5 The macrophage-epithelial repair assay (MERA) reveals that macrophage intrinsic TFF2 drives epithelial proliferation and barrier restoration. a Schematic showing MERA conceptual design. b Trans-epithelial resistance. (TER) values of transwell inserts containing primary tracheal epithelia or bone marrow macrophages $(B M M \varphi)$ cultured alone. c TER values following scratch wounding of epithelia in the presence or absence of WT BMM $\varphi$. d, e TER values following epithelial injury in the presence of d WT Vs. IL-4R $\alpha^{-/-}$BMM $\varphi$ and e WT vs. TFF2 ${ }^{-/-}$BMM $\varphi$. f Levels of TFF2 in MERA cultures with no BMM $\varphi$, WT BMM $\varphi$, TFF2 ${ }^{-/-}$BMM $\varphi$ or IL-4R $\alpha^{-/-}$BMM $\varphi$. Symbols represent individual wells. g Gating strategy to identify live epithelial cells recovered from MERA wells that express junctional adhesion molecule (JAM)-1 (R1). h-I Representative flow plots showing BrdU incorporation in R1 from " $\mathbf{g}$ " on d4 post-scratch wounding $\mathbf{h}$ in the absence of M $\varphi$ or in the presence of $\mathbf{i}$ WT BMM $\varphi$, j TFF2 ${ }^{-/-}$BMM $\varphi$, and $\mathbf{k}$ IL-4Ro ${ }^{--}$BMM $\varphi$. I BrdU incorporation on d4 post-scratch wounding following treatment with $0.5 \mathrm{ng} / \mathrm{ml}$ rTFF2 in the absence of $\mathrm{BMM} \varphi$. $\mathbf{m}$ Quantification of $\mathrm{BrdU}^{+}$epithelial cells as identified in $\mathbf{h}-\mathbf{l} . \mathbf{n}=3-6 /$ group. $\mathbf{n}$ TER values after scratch wounding of epithelia in the presence of rTFF2 $(0.5$ or $5 \mathrm{ng} / \mathrm{ml})$. o TER values following scratch wounding of WT vs. TFF2 ${ }^{-/-}$epithelia in the presence of WT or $\mathrm{TFF}^{-1-}$ alveolar macrophages. p, q MERA using AT2 co-cultured without BMM or with WT vs. TFF2 ${ }^{-1-}$ BMM. p Flow plots and $\mathbf{q}$ quantification of $\mathrm{EdU}^{+}$cells. $\mathbf{r}$ TER values following scratch in wells with WT vs. TFF2 ${ }^{-1-}$ BMM. Data represent $2-4$ independent experiments. ${ }^{*} p<0.05 ;{ }^{* *} p<0.01$, and ${ }^{* * *} p<0.005$ as determined by one-way ANOVA or $t$-test

(Fig. 6c). Real-time PCR quantification of Wnt4 and Wnt16 mRNA transcript levels in $\mathrm{CD}_{103^{+}} \mathrm{DC}, \mathrm{IM}$, and AM populations FACSsorted from lung tissues of WT and $\mathrm{TfF}^{-/-}$mice at $4 \mathrm{~d}$ post N.b (Supplementary Figure 3a) confirmed that TFF2 deficiency impaired Wnt4 expression in AM (Fig. 6d, e), but did not alter mRNA expression for Arg1, Retnla and Nos2 (Supplementary Figure 5c-e).

To confirm that non-canonical Wnt signaling functioned in the same pathway as TFF2 in the context of N.b.-induced lung injury, CD11 $c^{\text {Cre }}$ and CD11 Cre TFF2 ${ }^{\text {flox }}$ mice were administered either an rWnt4/Wnt16/R-spondin 1 cocktail $(1 \mu \mathrm{g})$ or saline control (vehicle). At d4 post-infection, rWnt4/Wnt16/R-spondin treatment caused a 2 -fold increase in the percentage of $\mathrm{EpCAM}^{+} \mathrm{BrdU}^{+} \mathrm{pro}^{-\mathrm{Spc}^{+}}$cell populations recovered from the distal lung compartment of the CD11 $\mathrm{C}^{\mathrm{Cre}}$ TFF2 ${ }^{\text {flox }}$ mice (Fig. 6f, g). No increased BrdU incorporation was noted in R-spondin only treated animals (Supplementary Figure $5 f$ ). These data imply that Wnt4/16 act downstream of TFF2 as part of $M \varphi$-driven repair processes that restore damaged epithelia.

\section{DISCUSSION}

Lung disorders affect millions worldwide, including sufferers of asthma, allergic rhinitis, bronchitis, COPD, lung cancer, emphysema, and pulmonary fibrosis. ${ }^{2}$ Persistent epithelial cell injury caused by smoking, allergens, pollutants, particulates, and pathogens all predispose towards chronic lung pathology. ${ }^{1}$ The prevailing hypothesis is that defective epithelial repair drives lung disease progression. ${ }^{36}$ Whereas epithelial-intrinsic mechanisms for regeneration have been a major focus, the question as to whether, and if so, how leukocytes may regulate these processes is less well understood. $\mathrm{M} \varphi$ seem a likely candidate, but there is debate over whether these cells are necessary for mucosal tissue repair. ${ }^{37}$ Herein, we demonstrate that $M \varphi$ significantly accelerate the repair of damaged respiratory epithelia in three different experimental systems. Repair of lung injury did not require an intact IL-4Ra, nor did it require the presence of $T, B$, or ILC subsets, although $T$ regulatory lymphocytes (Treg) can promote lung repair in the context of LPS-induced injury. ${ }^{38}$ Also, the mechanism seemed independent of $\mathrm{M} 2$ cells or ILC, ${ }^{39}$ suggesting that stereotyped polarization is only necessary for lung tissue repair in certain contexts. Recently, Lechner et al. reported that lung regeneration post-pneumonectomy did require $\mathrm{M} 2$ and ILC2, further indicating the importance of biological context. ${ }^{24}$ Instead, our data show M $\varphi$ induced epithelia to proliferate through TFF2 production, a cytokine previously considered released only from damaged epithelia. Thus, lung $M \varphi$ are an important ancillary source of this critical reparative cytokine.

$M \varphi$ reside in virtually every organ, where tissue-specific cues instruct unique transcriptional signatures in resident and emigrant $M \varphi$ to facilitate host defense, immunoregulation, and tissue homeostasis. ${ }^{40}$ Lung $\mathrm{M} \varphi$ (AM and IM) have been long recognized as immunosuppressive cells that mediate efferocytosis, and phagocytic clearance of inhaled particles and pathogens. Communication between $\mathrm{AM}$ and alveolar epithelia enforces an immunosuppressive lung environment, ${ }^{41}$ but whether such crosstalk regulates epithelial proliferation remained obscure. AMderived TGF- $\beta$ promotes Foxp ${ }^{+}{ }^{+}$Treg expansion, ${ }^{42}$ but TGF- $\beta$ promotes fibrosis and restricts epithelial cell proliferation. ${ }^{43}$ Thus, our demonstration that lung $M \varphi$ deletion reduced both epithelial proliferation and the rebound in lung function prompted our investigation of $M \varphi$-derived molecules that induced lung repair.

Hookworms damage alveolar architecture during their circuitous migration from skin to $\mathrm{Gl}$ tract, which is ideal to study infectious lung injury. N.b. larvae enter the lung within $24 \mathrm{~h}$ and cause petechial hemorrhage for 3 days before parasites egress to infest the Gl tract. ${ }^{44,45}$ IL-4Ra-driven M2 cells suppress pulmonary IL-17 responses during N.b infection, ${ }^{46}$ but whether Type 2 responses also promoted lung tissue regeneration was unclear. We found that IL-4Ra deficiency did not reduce infection-induced epithelial proliferation or barrier restoration, implying that IL-4Radependent M2 cells were non-essential for these processes. However, RNAseq analysis revealed M2-associated gene induction following exposure to damaged epithelia indicating that $M \varphi$ can "sense" tissue damage and undergo prototypical M2 polarization. Hookworm injury induced TFF2 expression within large mononuclear cells in a pattern similar to hemorrhagic spots caused by the larvae. In fact, Tff2 mRNA transcripts were induced in multiple myeloid populations upon hookworm infection (AM, IM, and $103^{+}$ DC). Tff2 mRNA expression has been noted in spleen and leukocyte populations and most recently in memory $\mathrm{CD}^{+}$ T cells. ${ }^{21}$ Because larvae significantly disrupt alveolar architecture, it is conceivable that replacement of dead/damaged AT1 cells requires proliferative expansion of distal lung progenitors. Although there are technical caveats with the use of flow cytometry and planimetry leaving stereology as the sole approach recommended by the American Thoracic Society for quantitation of epithelial cell number and potentially ATII expansion, ${ }^{47}$ we demonstrated that AT2 proliferation was impaired in the context of hookworm injury. Bleomycin-treated CD11 $c^{\text {Cre }}$ TFF2 ${ }^{\text {flox }}$ mice had a transient reduction of TFF2 levels, increased lung injury, greater weight loss, and defective expansion of AT2 cells as compared to CD11c Cre controls. Defective expansion of AT2 suggests that TFF2 derived from myeloid cells may regulate alveolar cell progenitor biology. In support of this notion, TFF2 transactivates GATA6, ${ }^{48}$ a transcription factor that drives epithelial stem cell development in the airway. ${ }^{49}$ We speculate that lung $M \varphi$ enter a regenerative stem cell niche, perhaps with lipofibroblasts ${ }^{50}$ similar to how intestinal $M \varphi$ reside at stem cell niches of intestinal crypts to facilitate regeneration. ${ }^{51}$

Our data show that TFF2 did not drive strong proliferation per se, but was required for expression of $M \varphi$-derived Wnt4 and Wnt16. Reconstitution experiments demonstrated that Wnt4/ Wnt16 increased AT2 proliferation in CD11 $c^{\text {Cre }}$ TFF2 ${ }^{\text {flox }}$ mice, but not the CD11 $\mathrm{C}^{\mathrm{Cre}}$ controls, further suggesting that Wnt production was downstream of TFF2. Wnt signaling serves a major role in lung 


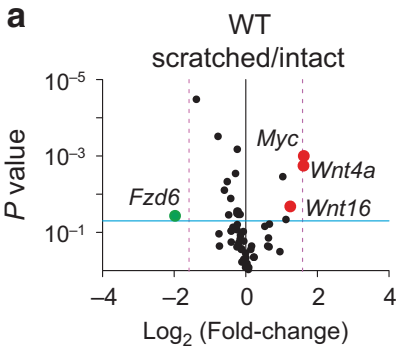

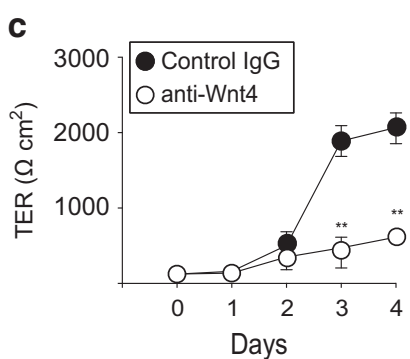

Wnt16
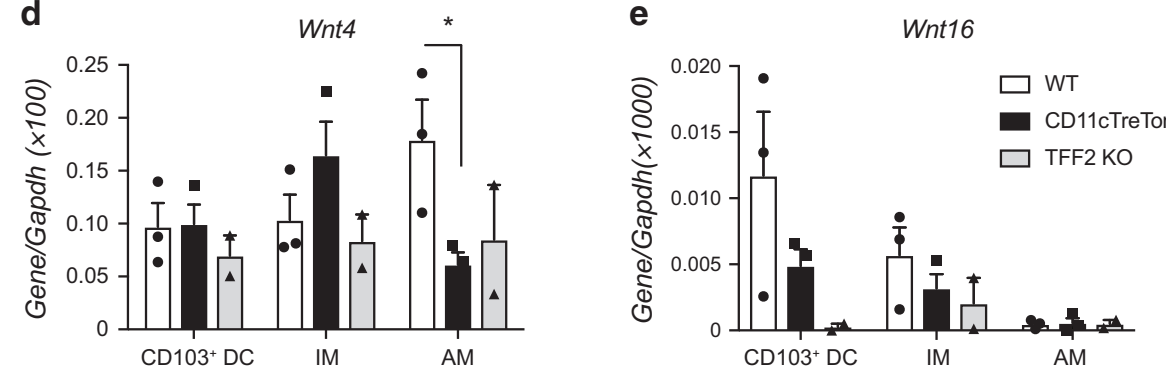

Wnt4/Wnt 16 + R-spondin

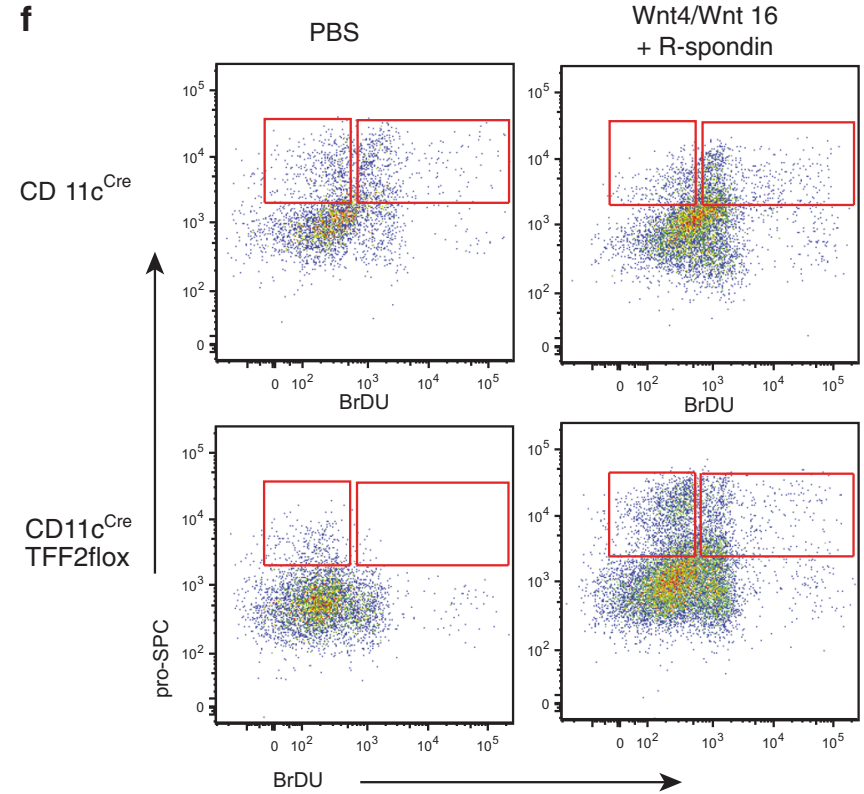

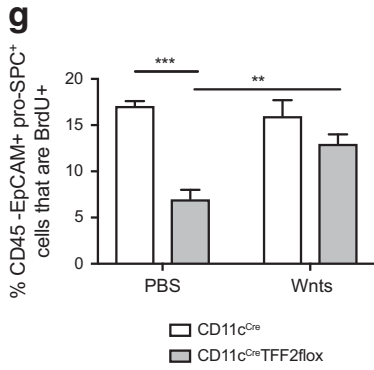

Fig. 6 TFF2 is necessary for myeloid-derived non-canonical Wnt4 and Wnt16 expression. a, b Volcano plots showing results of a cDNA-based screen for Wnt pathway target genes expressed as the fold-difference between a WT M $\varphi$ exposed to damaged or quiescent epithelia and b between WT M $\varphi$ vs. TFF2 ${ }^{-/-}$M $\varphi$ exposed to damaged epithelia. BMM $\varphi$ were recovered at d4 of MERA for analysis. Each point represents mean of three biological replicates. c TER values during MERA with WT M $\varphi$ in the presence of anti-Wnt4a mAb or control lgG. d, e Flow-sorted $\mathrm{AM}, \mathrm{IM}$ and $\mathrm{CD} 103^{+} \mathrm{DC}$ from WT or TFF2 KO lungs at $\mathrm{d} 4$ after infection were analyzed for mRNA levels of $\mathbf{d}$ Wnt4 and e Wnt $16 . \mathbf{f}$ Representative flow plots and $\mathbf{g}$ quantification of $\mathrm{BrdU}^{+} \mathrm{SpC}^{+}$epithelia from distal lung digest cells pre-gated on the live, $\mathrm{CD}^{-} 5^{-}, \mathrm{EpCAM}^{+}$population for each designated genotype following i.n. administration of rWnt4/16 + R-Spondin 1 cocktail $(1 \mu \mathrm{g} / \mathrm{mouse}, 2$ doses) or saline and analyzed by flow cytometry at $\mathrm{d} 4$ following N.b. infection ( $n=5$ /group). Graphs show Mean \pm SEM. ${ }^{*} p<0.05 ;{ }^{* *} p<0.01 ;$ and ${ }^{* * *} p<0.005$ as determined by ANOVA or Student's $t$-test

pulmonary regeneration in the context of development and postinjury. ${ }^{3,4}$ Wnt4 promotes mammalian lung development ${ }^{52}$ and induces Wnt16 transcription, suggesting that these molecules work in a concerted manner. ${ }^{53}$ Fibroblasts have been shown to exist in a regenerative niche with ATII cells to stimulate Wnt production. ${ }^{54}$ Recently it was shown that a sub-population of airway epithelial progenitors within the ATII population are driven to expand under Wnt signaling. ${ }^{55}$ However, our study is the first to implicate myeloid derived Wnt production, namely Wnt4 and Wnt16 as an additional mechanism of lung repair. Our results are consistent with data from other systems showing that $M \varphi$-derived
Wnt's regulate ocular development, hepatocyte specification, and regeneration of kidney and intestine. ${ }^{13,56-58}$

$\mathrm{M} \varphi$-derived regenerative factors may also drive malignant neoplasms. TFF2 is a negative prognostic indicator for certain tumors $^{59}$ and although TFF3, rather than TFF2, is an important biomarker of human lung cancer, ${ }^{60}$ it is plausible that a TFF2/Wnt axis can drive tumor progression. Humans with TFF2 polymorphisms that disrupt the trefoil domain have enhanced survival rates during cholangiocarcinoma suggesting that TFF2 may augment tumor cell growth or metastasis. ${ }^{61}$ Coincidentally, most tumors in cholangiocarcinoma patients contain Wnt-expressing tumor 
associated macrophages. ${ }^{62}$ We propose that autocrine TFF2 induces its own expression, ${ }^{63}$ promoting Camkk2b-dependent non-canonical Wnt production for regeneration of nearby epithelial precursors; a mechanism that drives repair of tissue damage caused by worms and cytotoxicity caused by chemicals.

In summary, we propose that epithelial cell proliferation and epithelial barrier restoration are accelerated by tissue $M \varphi$ through a TFF2-dependent mechanism. TFF2, in turn endows $M \varphi$ with the ability to produce molecules that include, but are not limited to, non-canonical Wnt's that induce epithelial cells to expand within damaged lung tissue. It is likely that similar mechanisms promote tissue repair at other mucosal surfaces.

\section{METHODS}

Animal procedures

Tet-DTA mice (B6.Cg-Tg(tetO-DTA)1Gfi/J, CD11c-Cre (B6.Cg-Tg (Itgax-cre)1-1Reiz/J), CD68-rtTa mice (B6.Cg-Tg(CD68-rtTA2S*M2) $3 \mathrm{Mpil} / \mathrm{Mmjax}$ ) were from the Jackson laboratory. C57BL/6 IL-4Ra ${ }^{-1-}$ and $\mathrm{TFF}^{-1-}$ mice have been described previously. ${ }^{9,22}$ Tff2 conditional knock-out td-Tomato fluorescent reporter mice (Tretom) generation in C57BL/6 E/S and FLP recombinase breeding was performed by genOway (Lyon, France). All studies were conducted with mice on the C57BL/ 6 background bred in house under specific-pathogen free barrier conditions at the San Francisco General Hospital or Univeristyof Pennsylvania vivarium. Mice used in experiments were between 6 and 12 weeks-old and all procedures were reviewed and approved by Institutional Animal Care and Use Committee at University of California at San Francisco (Protocol\# AN109782-01) and the University of Pennsylvania IACUC (Protocol\# 805911).

Lung pathology and Bleomycin

Gender-matched mice between 6 and 12 weeks old were placed in a plexiglass restrainer and given a subcutaneous inoculation of 600-750 larvae per mouse. Infective stage $\left(L_{3}\right)$ larvae were collected from 7 to 14-day old copro-cultures maintained in the laboratory at $25^{\circ} \mathrm{C}$. Parasites were collected with a modified Baermann apparatus and washed three times in sterile PBS containing Penicillin/Streptomycin prior to. For Bleomycin induced lung injury, mice were intratracheally instilled with $8.5 \mathrm{U} / \mathrm{Kg}$ of bleomycin sulfate (Millipore) on $\mathrm{d} 0$. Body mass was measured daily until the day of euthanasia as indicated in each experiment. To assess BrdU/EdU incorporation in both models, mice were injected i.p. with $2 \mathrm{mg}$ of BrdU or EdU solution (made with PBS) the $16-24 \mathrm{~h}$ before euthanasia.

Tissue macrophage depletion

To deplete lung myeloid cell populations, previously characterized CD68-rtTA and CD68-rtTAxTetO-DTA strains ${ }^{29}$ mice were inoculated i.n. with $250 \mathrm{ng}$ of anhydrotetracycline (Sigma-Aldrich, St. Louis, MO) every other day starting four days before N.b. infection. Mice treated with equal volume $(20 \mu \mathrm{l})$ of PBS were used as controls.

\section{Lung cell isolation}

To assess lung epithelial cell proliferation, distal lung digestion protocol was modified from work by Chapman et al. ${ }^{64}$ In brief, after cardiac puncture, the lungs were perfused with PBS through the right ventricle to remove blood. Then the lungs were instilled with $1 \mathrm{ml}$ dispase $(20 \mathrm{U} / \mathrm{ml})$, followed by $0.2 \mathrm{ml} 0.1 \%$ liquefied lowmelting agarose. After the agarose hardened, remove the lung and digest on a shaker for $45 \mathrm{~min}$, then disintegrate the lung with forceps and incubate for another $10 \mathrm{~min}$ on the shaker. At the end of incubation, collect cells and pass through 100 and $70-\mu$ strainers sequentially in order to obtain single cell suspension for fluorescent antibody staining followed by flow cytometry. For the MERA assay, ATII cell isolation was performed as previously described by Atochina-Vasserman et al. ${ }^{65}$ Mouse lungs were lavaged, perfused and inflated with $0.7 \mathrm{ml}$ dispase $(50 \mathrm{U} / \mathrm{ml}, \mathrm{BD}$ Biosciences) then tied off from the trachea. Isolated lungs were incubated $30 \mathrm{~min}$ at $37^{\circ} \mathrm{C}$, after which individual lobes were dissected away from large airways and mechanically dissociated with a Mcllwain tissue chopper (Metrohmm USA, Riverview, FL) then incubate at $37^{\circ} \mathrm{C}$ for $10 \mathrm{~min}$ in MEM + DNase I $(20 \mu \mathrm{g} / \mathrm{ml}$, Sigma). Cell digests were sequentially passed through 100 and $40 \mu \mathrm{m}$ strainers, followed by three rounds of $30 \mathrm{~min}$ adhesion on plastic tissue culture dishes to remove fibroblasts and mesenchymal cells. Non-adherent cells were collected and subjected to lineage depletion using Dynabeads ${ }^{\mathrm{TM}}$ kits (DC enrichment kit and T cell negative isolation kit, both from Thermo Fisher) to remove $\mathrm{CD}^{2} 5^{+}$cells. Recovered cells were cultured in HITES medium (Ham's F12 + $15 \mathrm{mM}$ HEPES $+0.8 \mathrm{mM} \mathrm{CaCl}_{2}+1 \%$ ITS Universal supplement (BD Biosciences)) with $10 \%$ FBS +50 nM Dexamethasone $+0.1 \mathrm{mM}$ 8-Br-cAMP $+0.1 \mathrm{mM}$ IBMX on matrigel $(1: 10$ dilution)-coated 12-well transwell inserts at $250 \mathrm{~K} /$ well for $24 \mathrm{~h}$ followed by the addition of recombinant human KGF $(10 \mathrm{ng} / \mathrm{ml}$, Sigma). Cells were cultured for 5-7 days before experiments with fresh media added every other day.

Confocal imaging of lung slices

For vital laser-scanning confocal imaging $400 \mu \mathrm{m}$ thick sections of lungs were prepared as previously described. ${ }^{31}$ Briefly, mice were euthanized using a lethal dose of $1.3 \%$ tribromoethanol (Avertin, Sigma-Aldrich) and exsanguinated. Exposed lungs were then intratracheally inflated with $1.2 \mathrm{ml}$ of $2.0 \%$ low melting temperature agarose (Fisher Scientific) at $37^{\circ} \mathrm{C}$, and solidified with cold PBS $\left(8-12^{\circ} \mathrm{C}\right)$. The left lobes were isolated, sliced into thick sections $(400 \mu \mathrm{m})$ with a Leica Vibratome VT1000S, mounted on plastic cover slips using Vetbond $(3 \mathrm{M})$, and then imaged on a temperature-controlled stage (Warner Instruments, Hamden, CT) maintained at $37^{\circ} \mathrm{C}$, while in constant perfusion with oxygenated (95\% O2; 5\% CO2) RPMI-1640 without phenol red. Images were acquired using a Nikon A1R microscope equipped with an automated Prior $X Y$ stage, following manufacturer's protocol and software, and the parameters described here. For excitation a $5 \mathrm{~W}$, 740-1000 nm tunable MaiTai HP (Newport, Irvine, CA) laser was used. A $20 \times 0.95$ N.A. water-immersion objective (Olympus XLUMPLFLN 20XW) was used, and a spatial resolution of 1.13 $\mu \mathrm{m} /$ pixel was achieved. Two $\mu \mathrm{m}$ Z-depth per plane was used for three-dimensional imaging. Images were recorded using the galvanometer-based scanning mode. For RFP excitation, $990 \mathrm{~nm}$ and a $650 / 50 \mathrm{~nm}$ emission band pass were used. Following three five-minute washes in HBSS, slices were mounted on coverslips and then imaged. Images were analyzed using Imaris (Bitplane).

$\mathrm{SpO}_{2}$ measurement

Blood oxygen levels were measured by MouseOx pulse oximeter from Starr Life Sciences (Oakmont, PA) following the manufacturer's protocol. Lungs were perfused with $10 \mathrm{ml}$ of $1 \mathrm{x}$ PBS through the left ventricle to remove blood from the vasculature then inflated and fixed with $10 \%$ buffered formalin at $20 \mathrm{mmHg}$ using a commercially available system by Braintree Scientific followed by overnight fixation in $10 \%$ neutral buffered formalin for fixation and paraffin embedding prior to histological staining and evaluation.

\section{Real time PCR and qPCR array}

Total RNA was harvested from tissues or cultured cells using RNeasy Mini kit (QIAGEN, Hilden, Germany). Real-time PCR reactions were run on CFX96 real-time PCR detection system (Bio-Rad, Hercules, CA). Gene expression is normalized to Gapdh and data were presented as Mean \pm SEM from the replicates. The Wnt pathway $\mathrm{RT}^{2}$ Profiler real-time $\mathrm{PCR}$ array, $\mathrm{RT}^{2}$ First Strand Kit and $\mathrm{SYBR}^{\circledR}$ Green $\mathrm{qPCR}$ Mastermix were all purchased from Qiagen. Real-time PCR reactions were carried out on Bio-Rad 
CFX96 system and data were analyzed using the $\Delta \Delta \mathrm{Ct}$ method as recommended in the manual.

Tracheal epithelial cell culture and MERA

Tracheal tissue was resected and perfused overnight with $0.5 \%$ protease (Sigma-Aldrich) in DMEM. On the next day, cells were flushed out and plated onto Matrigel ${ }^{\mathrm{TM}}$ (BD Biosciences, Bedford, MA)-coated 12-well Transwell chambers (Corning Inc., Corning, NY) in Ham's F12 and DMEM (1:1), supplemented with insulin $(5 \mathrm{mg} / \mathrm{ml})$, transferrin $(5 \mathrm{mg} / \mathrm{ml})$, epidermal growth factor $(10 \mathrm{ng} / \mathrm{ml})$, dexamethasone $(0.1 \mathrm{mM})$, cholera toxin $(10 \mathrm{ng} / \mathrm{ml})$, bovine hypothalamus extract $(15 \mathrm{mg} / \mathrm{ml})$, all-trans retinoic acid $(100 \mathrm{nM})$, and Rho-associated protein kinase (ROCK) inhibitor Y27632 (10 mM, STEMCELL Technologies, Cambridge, MA). Cells were kept in a $37^{\circ} \mathrm{C}$ incubator with $5 \% \mathrm{CO}_{2}$ for one week or until the trans-epithelial resistance (TER) values reached $1000 \Omega$ as determined by Millicell ERS-2 Volt-Ohm meter with the ERSS TX03 adjustable electrode set (both from EMD Millipore). MTECs were switched to an air-liquid interface (ALI) culture condition with MTEC differentiation media (DMEM and F12 (1:1) media supplemented with $100 \mathrm{U} / \mathrm{ml}$ penicillin, $100 \mathrm{U} / \mathrm{ml}$ streptomycin, $100 \mathrm{nM}$ all-trans retinoic acid, and 2\% NuSerum (BD Biosciences) for an additional 1-2 weeks. For MERA assays, bone marrow-derived hematopoietic cells were cultured in DMEM media supplemented with $10 \%$ FCS and culture supernatant of a mouse M-CSF secreting cell line. Three days after the initial plating, non-adherent cells were removed and fresh media were added into the culture. On day 4-6 macrophages were harvested and used in MERA. On the day of MERA experiment, Transwell inserts with MTECs were taken out of the wells and flipped over; macrophages were plated on the side opposite to MTECs and allowed $2 \mathrm{~h}$ for attachment at $37^{\circ} \mathrm{C}$. At the end of incubation period, the bottom side of inserts was rinsed gently with warm PBS before placed back to the plate. Cells were cultured in MTEC differentiation media (without alltrans retinoic acid) plus rMCSF containing supernatant (1:10-1:25) for up to 4 days during MERA. TER was measured daily with Millicell ERS-2 Volt-Ohm meter (EMD Millipore, Billerica, MA). For anti-Wnt4 treatments, a mixture of $20 \mathrm{ug} / \mathrm{ml}$ of polyclonal goat anti-mouse Wnt4 (R\&D Systems AF475) and $20 \mu \mathrm{g} / \mathrm{ml}$ of rat antimouse Wnt4 IgG2a (R\&D Systems MAB475) was added to basolateral side of MERA wells on day 0 and day 2 of experiments. As control, a mixture of normal goat IgG (R\&D Systems AB-108-C) and rat IgG2a (clone GL117) at the same concentration was added. For BrdU/EdU incorporation assays, cells were treated with $10 \mu \mathrm{M}$ BrdU/EdU solution $16 \mathrm{~h}$ before harvesting.

Flow cytometry and immunohistochemistry

All the following antibodies were purchased from BioLegend (San Diego, CA): rat anti-mouse CD31 (clone 390), rat anti-mouse CD45 (30-F11), rat anti-mouse CD49f/6 integrin $(\mathrm{GoH} 3)$, rat anti-mouse CD104/4 integrin (346-11 A), rat anti-mouse F4/80 (BM8), rat antimouse Ly6C (HK1.4),rat anti-mouse Ly6G/Gr1 (RB6-8C5), Ly6C (1A8), and rat anti-mouse CD326/EpCAM (G8.8). Hamster antimouse Podoplanin/T1 (eBio8.1.1), rat anti-mouse CD11b (M1/70), hamster anti-mouse CD11c (N418), mouse anti-mouse CD45.1 (A20), rat anti-mouse I-A/I-E (M5/114.15.2), and hamster antimouse CD103 (2E7) were purchased from eBioscience (San Diego, CA). Cell viability was determined by LIVE/DEAD ${ }^{\circledR}$ Fixable Aqua Stain (Life Technologies). Rat anti-mouse Siglec-F (E50-2440) and rat anti-mouse CD45.2 (clone 104) were purchased from BD Biosciences. BrdU staining was performed with BrdU Flow kits from BD Biosciences following manufacturer's protocol. Intracellular staining of $\mathrm{SpC}$ was achieved by use of rabbit anti-mouse ProSpC (Seven Hills Bioreagents, Cincinnati, $\mathrm{OH}$ ) in conjunction with fluorescence-labeled donkey anti-rabbit secondary antibody (Jackson ImmunoResearch, West Grove, PA). Flow cytometry was carried out on LSRII or Fortessa (BD Biosciences) with BD FACSDiva software. Flow-based cell sorting was performed using BD
FACSAria sorter. For immunohistochemistry, perfused lung tissues were formalin fixed and paraffin embedded and sectioned at $3-5-\mu$ thickness. Polyclonal goat anti-mouse Ym1 (R\&D Systems,) and rabbit anti-mouse Ki67 (AbCam, Cambridge, MA), with secondary Alexa Fluor 488-donkey anti-goat and Cy3-donkey anti-rabbit antibody (both from Jackson ImmunoResearch, West Grove, PA) respectively, were used in co-staining. Hard $\mathrm{Set}^{\mathrm{TM}}$ mounting medium containing DAPI was purchased from Vector Laboratories (Burlingame, CA). Images were acquired on Leica DM600B microscope with LAS software.

ELISA and BALF total protein

Mouse TFF2 ELISA kit was purchased from United States Biological (Salem, MA). To assess BALF protein level, mouse lungs were lavaged with $1 \mathrm{ml}$ PBS after euthanasia and total protein concentration in BALF was measured using Pierce ${ }^{\mathrm{TM}}$ BCA protein assay kit (Thermo Fisher) following the manufacture's protocol.

\section{Recombinant Wnt treatment}

All reagents, including carrier-free recombinant mouse Wnt4, human Wnt16, and mouse R-Spondin 1, were purchased from R\&D Systems. On the day of Nippostrongylus infection, mice were given $300 \mathrm{ng}$ of each recombinant protein or equal volume of sterile PBS intranasally. A second dose of mixed Wnts and R-Spondin 1 were administered on day 2 post-infection.

\section{Statistics}

All data points represent biological replicates of experiments analyzed using Prism (GraphPad, La Jolla, CA). Fluorescence microscopy images are representative of five different highpower fields (hpf) from 3 wild-type C57BL/6 mice. Mean \pm standard error were compared using Student's $t$-test for two groups and one-way ANOVA for three or more groups with significance determined as $p<0.05$.

\section{ACKNOWLEDGEMENTS}

D.R.H. is supported by NIH (Al095289, GM083204, UO1Al125940) and the Burroughs Wellcome Fund. We thank Dean Sheppard and James Frank for critical comments.

\section{AUTHOR CONTRIBUTIONS}

L.-Y.H., D.S., T.K.O., J.K., and W.N. performed experiments, L.-Y.H., D.S., T.K.O., W.N., M.F. B, M.F.K., N.A.C., A.E.V. and D.R.H., analyzed data, D.R.H. conceived the study and D.R. H., N.A.C., A.E.V., and L.-Y.H wrote the manuscript.

\section{ADDITIONAL INFORMATION}

The online version of this article (https://doi.org/10.1038/s41385-018-0096-2) contains supplementary material, which is available to authorized users.

Competing interests: The authors declare no competing interests.

\section{REFERENCES}

1. Whitsett, J. A. \& Alenghat, T. Respiratory epithelial cells orchestrate pulmonary innate immunity. Nat. Immunol. 16, 27-35 (2015).

2. Hogan, B. L., Barkauskas, C. E., Chapman, H. A., Epstein, J. A., Jain, R. \& Hsia, C. C. et al. Repair and regeneration of the respiratory system: complexity, plasticity, and mechanisms of lung stem cell function. Cell Stem Cell 15, 123-38 (2014).

3. Vaughan, A. E., Brumwell, A. N., Xi, Y., Gotts, J. E., Brownfield, D. G. \& Treutlein, B. et al. Lineage-negative progenitors mobilize to regenerate lung epithelium after major injury. Nature 517, 621-5 (2015).

4. Vaughan, A. E. \& Chapman, H. A. Regenerative activity of the lung after epithelial injury. Biochim Biophys. Acta 1832, 922-30 (2013).

5. Kopf, M., Schneider, C. \& Nobs, S. P. The development and function of lungresident macrophages and dendritic cells. Nat. Immunol. 16, 36-44 (2015).

6. Schneider, C., Nobs, S. P., Heer, A. K., Kurrer, M., Klinke, G. \& van Rooijen, N. et al. Alveolar macrophages are essential for protection from respiratory failure and 
associated morbidity following influenza virus infection. PLoS Pathog. 10, e1004053 (2014)

7. Edwards, J. P., Zhang, X., Frauwirth, K. A. \& Mosser, D. M. Biochemical and functional characterization of three activated macrophage populations. J. Leukoc. Biol. 80, 1298-307 (2006).

8. Mosser, D. M. \& Edwards, J. P. Exploring the full spectrum of macrophage activation. Nat. Rev. Immunol. 8, 958-69 (2008).

9. Herbert, D. R., Holscher, C., Mohrs, M., Arendse, B., Schwegmann, A. \& Radwanska, $M$. et al. Alternative macrophage activation is essential for survival during schistosomiasis and downmodulates $\mathrm{T}$ helper 1 responses and immunopathology. Immunity 20, 623-35 (2004).

10. Murray, P. J., Allen, J. E., Biswas, S. K., Fisher, E. A., Gilroy, D. W. \& Goerdt, S. et al. Macrophage activation and polarization: nomenclature and experimental guidelines. Immunity 41, 14-20 (2014).

11. Murray, P. J. \& Wynn, T. A. Protective and pathogenic functions of macrophage subsets. Nat. Rev. Immunol. 11, 723-37 (2011).

12. Van Dyken, S. J. \& Locksley, R. M. Interleukin-4- and interleukin-13-mediated alternatively activated macrophages: roles in homeostasis and disease. Annu Rev. Immunol. 31, 317-43 (2013).

13. Saha, S., Aranda, E., Hayakawa, Y., Bhanja, P., Atay, S. \& Brodin, N. P. et al. Macrophage-derived extracellular vesicle-packaged WNTs rescue intestinal stem cells and enhance survival after radiation injury. Nat. Commun. 7, 13096 (2016).

14. Yeo, E. J., Cassetta, L., Qian, B. Z., Lewkowich, I., Li, J. F. \& Stefater, J. A. et al. Myeloid WNT7b mediates the angiogenic switch and metastasis in breast cancer. Cancer Res. 74, 2962-73 (2014).

15. Clevers, H. \& Nusse, R. Wnt/beta-catenin signaling and disease. Cell 149 1192-205 (2012)

16. Schulte, G. \& Bryja, V. The Frizzled family of unconventional G-protein-coupled receptors. Trends Pharmacol. Sci. 28, 518-25 (2007).

17. Taupin, D. \& Podolsky, D. K. Trefoil factors: initiators of mucosal healing. Nat. Rev. Mol. Cell Biol. 4, 721-32 (2003).

18. Aamann, L., Vestergaard, E. M. \& Gronbaek, H. Trefoil factors in inflammatory bowel disease. World J. Gastroenterol. 20, 3223-30 (2014).

19. Taupin, D. R., Kinoshita, K. \& Podolsky, D. K. Intestinal trefoil factor confers colonic epithelial resistance to apoptosis. Proc. Natl Acad. Sci. USA 97, 799-804 (2000).

20. McBerry, C., Egan, C. E., Rani, R., Yang, Y., Wu, D. \& Boespflug, N. et al. Trefoil factor 2 negatively regulates type 1 immunity against Toxoplasma gondii. J. Immunol. 189, 3078-84 (2012).

21. Dubeykovskaya, Z., Si, Y., Chen, X., Worthley, D. L., Renz, B. W. \& Urbanska, A. M. et al. Neural innervation stimulates splenic TFF2 to arrest myeloid cell expansion and cancer. Nat. Commun. 7, 10517 (2016).

22. Wills-Karp, M., Rani, R., Dienger, K., Lewkowich, I., Fox, J. G. \& Perkins, C. et al. Trefoil factor 2 rapidly induces interleukin 33 to promote type 2 immunity during allergic asthma and hookworm infection. J. Exp. Med. 209, 607-22 (2012).

23. Hung, L. Y., Oniskey, T. K., Sen, D., Krummel, M. F., Vaughan, A. E. \& Cohen, N. A. et al. Trefoil factor 2 promotes type 2 immunity and lung repair through intrinsic roles in hematopoietic and nonhematopoietic cells. Am. J. Pathol. 188, 1161-70 (2018).

24. Lechner, A. J., Driver, I. H., Lee, J., Conroy, C. M., Nagle, A. \& Locksley, R. M. et al. Recruited monocytes and type 2 immunity promote lung regeneration following pneumonectomy. Cell Stem Cell 21, 120-34 e127 (2017).

25. Craig, J. M. \& Scott, A. L. Helminths in the lungs. Parasite Immunol. 36, 463-74 (2014).

26. Jenkins, S. J., Ruckerl, D., Thomas, G. D., Hewitson, J. P., Duncan, S. \& Brombacher, F. et al. IL-4 directly signals tissue-resident macrophages to proliferate beyond homeostatic levels controlled by CSF-1. J. Exp. Med. 210, 2477-91 (2013).

27. Jenkins, S. J., Ruckerl, D., Cook, P. C., Jones, L. H., Finkelman, F. D. \& van Rooijen, N et al. Local macrophage proliferation, rather than recruitment from the blood, is a signature of TH2 inflammation. Science 332, 1284-8 (2011).

28. Nieves, W., Hung, L. Y., Oniskey, T. K., Boon, L., Foretz, M. \& Viollet, B. et al. Myeloid-restricted AMPKalpha1 promotes host immunity and protects against IL12/23p40-dependent lung injury during Hookworm infection. J. Immunol. 196, 4632-40 (2016)

29. Gheryani, N., Coffelt, S. B., Gartland, A., Rumney, R. M., Kiss-Toth, E. \& Lewis, C. E. et al. Generation of a novel mouse model for the inducible depletion of macrophages in vivo. Genesis 51, 41-49 (2013).

30. Farrell, J. J., Taupin, D., Koh, T. J., Chen, D., Zhao, C. M. \& Podolsky, D. K. et al. TFF2/ SP-deficient mice show decreased gastric proliferation, increased acid secretion, and increased susceptibility to NSAID injury. J. Clin. Invest. 109, 193-204 (2002).

31. Thornton, E. E., Krummel, M. F. \& Looney, M. R. Live imaging of the lung. Curr. Protoc. Cytom. 12, 28 (2012).

32. van Rijt, L. S., Jung, S., Kleinjan, A., Vos, N., Willart, M. \& Duez, C. et al. In vivo depletion of lung $\mathrm{CD} 11 \mathrm{c}+$ dendritic cells during allergen challenge abrogates the characteristic features of asthma. J. Exp. Med. 201, 981-91 (2005).
33. Wilson, M. S., Madala, S. K., Ramalingam, T. R., Gochuico, B. R., Rosas, I. O. \& Cheever, A. W. et al. Bleomycin and IL-1beta-mediated pulmonary fibrosis is IL17A dependent. J. Exp. Med. 207, 535-52 (2010).

34. Qu, F., Wang, J., Xu, N., Liu, C., Li, S. \& Wang, N. et al. WNT3A modulates chondrogenesis via canonical and non-canonical Wnt pathways in MSCs. Front Biosci. 18, 493-503 (2013)

35. Wang, Q., Symes, A. J., Kane, C. A., Freeman, A., Nariculam, J. \& Munson, P. et al. A novel role for $\mathrm{Wnt} / \mathrm{Ca} 2+$ signaling in actin cytoskeleton remodeling and cell motility in prostate cancer. PLOS ONE 5, e10456 (2010).

36. Wynn, T. A. Integrating mechanisms of pulmonary fibrosis. J. Exp. Med. 208 1339-50 (2011).

37. Martin, P., D'Souza, D., Martin, J., Grose, R., Cooper, L. \& Maki, R. et al. Wound healing in the PU.1 null mouse-tissue repair is not dependent on inflammatory cells. Curr. Biol. 13, 1122-8 (2003).

38. Mock, J. R., Garibaldi, B. T., Aggarwal, N. R., Jenkins, J., Limjunyawong, N. \& Singer, B. D. et al. Foxp3+ regulatory $T$ cells promote lung epithelial proliferation. Mucosal Immunol. 7, 1440-51 (2014).

39. Monticelli, L. A., Sonnenberg, G. F., Abt, M. C., Alenghat, T., Ziegler, C. G. \& Doering, T. A. et al. Innate lymphoid cells promote lung-tissue homeostasis after infection with influenza virus. Nat. Immunol. 12, 1045-54 (2011).

40. Lavin, Y., Winter, D., Blecher-Gonen, R., David, E., Keren-Shaul, H. \& Merad, M. et al. Tissue-resident macrophage enhancer landscapes are shaped by the local microenvironment. Cell 159, 1312-26 (2014).

41. Westphalen, K., Gusarova, G. A., Islam, M. N., Subramanian, M., Cohen, T. S. \& Prince, A. S. et al. Sessile alveolar macrophages communicate with alveolar epithelium to modulate immunity. Nature 506, 503-6 (2014).

42. Soroosh, P., Doherty, T. A., Duan, W., Mehta, A. K., Choi, H. \& Adams, Y. F. et al Lung-resident tissue macrophages generate Foxp3+ regulatory $\mathrm{T}$ cells and promote airway tolerance. J. Exp. Med. 210, 775-88 (2013).

43. Siegel, P. M. \& Massague, J. Cytostatic and apoptotic actions of TGF-beta in homeostasis and cancer. Nat. Rev. Cancer 3, 807-21 (2003).

44. Hung, L. Y., Lewkowich, I. P., Dawson, L. A., Downey, J., Yang, Y. \& Smith, D. E. et al. IL-33 drives biphasic IL-13 production for noncanonical Type 2 immunity against hookworms. Proc. Natl Acad. Sci. USA 110, 282-7 (2013).

45. Herbert, D. R., Yang, J. Q., Hogan, S. P., Groschwitz, K., Khodoun, M. \& Munitz, A. et al. Intestinal epithelial cell secretion of RELM-beta protects against gastrointestinal worm infection. J. Exp. Med. 206, 2947-57 (2009).

46. Chen, F., Liu, Z., Wu, W., Rozo, C., Bowdridge, S. \& Millman, A. et al. An essential role for TH2-type responses in limiting acute tissue damage during experimental helminth infection. Nat. Med. 18, 260-6 (2012).

47. Jansing, N. L., Patel, N., McClendon, J., Redente, E. F., Henson, P. M. \& Tuder, R. M. et al. Flow cytometry underestimates and planimetry overestimates alveolar epithelial type 2 cell expansion after lung injury. Am. J. Respir. Crit. Care Med. 198 390-2 (2018).

48. Al-azzeh, E. D., Fegert, P., Blin, N. \& Gott, P. Transcription factor GATA-6 activates expression of gastroprotective trefoil genes TFF1 and TFF2. Biochim. Biophys. Acta 1490, 324-32 (2000)

49. Zhang, Y., Goss, A. M., Cohen, E. D., Kadzik, R., Lepore, J. J. \& Muthukumaraswamy, K. et al. A Gata6-Wnt pathway required for epithelial stem cell development and airway regeneration. Nat. Genet. 40, 862-70 (2008).

50. Barkauskas, C. E., Cronce, M. J., Rackley, C. R., Bowie, E. J., Keene, D. R. \& Stripp, B. R. et al. Type 2 alveolar cells are stem cells in adult lung. J. Clin. Invest. 123, 3025-36 (2013).

51. Pull, S. L., Doherty, J. M., Mills, J. C., Gordon, J. I. \& Stappenbeck, T. S. Activated macrophages are an adaptive element of the colonic epithelial progenitor niche necessary for regenerative responses to injury. Proc. Natl Acad. Sci. USA 102, 99-104 (2005).

52. Caprioli, A., Villasenor, A., Wylie, L. A., Braitsch, C., Marty-Santos, L. \& Barry, D. et al. Wnt4 is essential to normal mammalian lung development. Dev. Biol. 406, 222-34 (2015).

53. Kim, Y. C., Clark, R. J., Pelegri, F. \& Alexander, C. M. Wnt4 is not sufficient to induce lobuloalveolar mammary development. BMC Dev. Biol. 9, 55 (2009).

54. Nabhan, A. N., Brownfield, D. G., Harbury, P. B., Krasnow, M. A. \& Desai, T. J. Singlecell Wnt signaling niches maintain stemness of alveolar type 2 cells. Science $\mathbf{3 5 9}$ 1118-23 (2018)

55. Zacharias, W. J., Frank, D. B., Zepp, J. A., Morley, M. P., Alkhaleel, F. A. \& Kong, J. et al. Regeneration of the lung alveolus by an evolutionarily conserved epithelial progenitor. Nature 555, 251-5 (2018).

56. Lobov, I. B., Rao, S., Carroll, T. J., Vallance, J. E., Ito, M. \& Ondr, J. K. et al. WNT7b mediates macrophage-induced programmed cell death in patterning of the vasculature. Nature 437, 417-21 (2005).

57. Boulter, L., Govaere, O., Bird, T. G., Radulescu, S., Ramachandran, P. \& Pellicoro, A. et al. Macrophage-derived Wnt opposes Notch signaling to specify hepatic progenitor cell fate in chronic liver disease. Nat. Med. 18, 572-9 (2012). 
58. Lin, S. L., Li, B., Rao, S., Yeo, E. J., Hudson, T. E. \& Nowlin, B. T. et al. Macrophage Wnt7b is critical for kidney repair and regeneration. Proc. Natl Acad. Sci. USA 107, 4194-9 (2010).

59. Kosriwong, K., Menheniott, T. R., Giraud, A. S., Jearanaikoon, P., Sripa, B. \& Limpaiboon, T. Trefoil factors: tumor progression markers and mitogens via EGFR/MAPK activation in cholangiocarcinoma. World J. Gastroenterol. 17, 1631-41 (2011).

60. Qu, Y., Yang, Y., Ma, D. \& Xiao, W. Increased trefoil factor 3 levels in the serum of patients with three major histological subtypes of lung cancer. Oncol. Rep. 27, 1277-83 (2012).

61. Kamlua, S., Patrakitkomjorn, S., Jearanaikoon, P., Menheniott, T. R., Giraud, A. S. \& Limpaiboon, T. A novel TFF2 splice variant (EX2TFF2) correlates with longer overall survival time in cholangiocarcinoma. Oncol. Rep. 27, 1207-12 (2012).

62. Boulter, L., Guest, R. V., Kendall, T. J., Wilson, D. H., Wojtacha, D. \& Robson, A. J. et al. WNT signaling drives cholangiocarcinoma growth and can be pharmacologically inhibited. J. Clin. Invest. 125, 1269-85 (2015).

63. Bulitta, C. J., Fleming, J. V., Raychowdhury, R., Taupin, D., Rosenberg, I. \& Wang, T. C. Autoinduction of the trefoil factor 2 (TFF2) promoter requires an upstream cisacting element. Biochem. Biophys. Res. Commun. 293, 366-74 (2002).

64. Chapman, H. A., Li, X., Alexander, J. P., Brumwell, A., Lorizio, W. \& Tan, K. et al. Integrin alpha6beta4 identifies an adult distal lung epithelial population with regenerative potential in mice. J. Clin. Invest. 121, 2855-62 (2011).
65. Atochina-Vasserman, E. N., Bates, S. R., Zhang, P., Abramova, H., Zhang, Z. \& Gonzales, L. et al. Early alveolar epithelial dysfunction promotes lung inflammation in a mouse model of Hermansky-Pudlak syndrome. Am. J. Respir. Crit. Care Med. 184, 449-58 (2011).

(i) Open Access This article is licensed under a Creative Commons By Attribution 4.0 International License, which permits use, sharing, adaptation, distribution and reproduction in any medium or format, as long as you give appropriate credit to the original author(s) and the source, provide a link to the Creative Commons license, and indicate if changes were made. The images or other third party material in this article are included in the article's Creative Commons license, unless indicated otherwise in a credit line to the material. If material is not included in the article's Creative Commons license and your intended use is not permitted by statutory regulation or exceeds the permitted use, you will need to obtain permission directly from the copyright holder. To view a copy of this license, visit http://creativecommons. org/licenses/by/4.0/.

(c) The Author(s) 2018 